\title{
UNA APROXIMACIÓN A ALGUNOS MARCADORES CON FUNCIÓN TEXTUAL DE «RESUMEN», «CONCLUSIÓN»Y «CIERRE»
}

\author{
NANCY VÁZquez Veiga \\ (Universidad de La Coruña)
}

\begin{abstract}
RESUMEN
The aim of this paper is to provide a linguistic description of some Spanish discourse markers with the functions of «summary», «conclusion» and «closing».

These markers are: en resumen, resumen, en resumidas cuentas, en suma, total, en conclusión, conclusión, en fin, finalmente and por último.

This description will include a study of the discursive uses of each marker through an analysis of, among others, their possible lexicalization, the pertinence of their presence, the type of syntactic relation and their degree of autonomy.
\end{abstract}

\section{INTRODUCCIÓN}

El hablante tiene a su disposición toda una serie de procedimientos de cohesión para poder organizar su discurso y hacer de éste una unidad coherente. Dentro de tales procedimientos hay que situar a los marcadores textuales, ya que éstos se encargan de conectar los enunciados que conforman un texto.

Lamentablemente, a pesar de la importante labor que desempeñan dentro de la estructura de un texto, podemos afirmar que, en general, la tradición española, muy respetuosa con los límites que la oración le imponía, ha mostrado un interés muy escaso por el estudio de los marcadores. Sin embargo, debemos decir a su favor que muchos gramáticos han percibido, aunque no lo expongan explícitamente, que algunas piezas léxicas establecían conexiones que superaban el marco de la estructura oracional. Citemos, por poner un ejemplo, el último capítulo del Curso de Samuel Gili Gaya 1961, titulado «Enlaces ex traoracionales». Es casi un tópico comenzar los trabajos sobre estos elementos con una referencia, 
aunque sea breve, a Samuel Gili Gaya, porque, como dice $\mathrm{M}^{\mathbf{a}}$ Antonia Martín Zorraquino 1988, el capítulo mencionado 'constituye, sin duda, un verdadero esbozo de «gramática del texto» o de «gramática transoracional» del español' (pág. 253).

Desde hace algunos años, se ha empezado a abordar el análisis de estas partículas desde diferentes perspectivas, pero la bibliografía con la que podemos contar para el español no es tan rica como la que se encuentra para otras lenguas, como el inglés o el francés ${ }^{1}$. De cualquier forma, dentro del ámbito hispano, ya empiezan a aparecer algunos estudios interesantes sobre estos elementos. Así, entre los autores que se han preocupado por estas cuestiones están: $M^{\mathbf{a}}$ Luz Gutiérrez Araus 1978; José Ortega Olivares 1986; Catalina Fuentes Rodríguez 1987; Humberto Mederos Martín 1988; Alfredo Álvarez Menéndez 1990; Manuel Casado Velarde 1991; Mª Antonia Martín Zorraquino 1988 y 1992; Antonio Briz 1993 y en prensa, etc. Por otro lado, las obras lexicográficas -Diccionario de uso del español (1966-1967) de $\mathrm{M}^{\mathrm{a}}$ Moliner; Diccionario académico (1992)...y algún estudio sobre la lengua coloquial —El español coloquial (original alemán de 1958; tercera ed. española 1978) de Werner Beinhauer, Aspectos del español hablado (1980) y Morfosintaxis del español coloquial (1992) de Ana Mª Vigara Tauste...- - son también instrumentos en los que aparecen observaciones útiles sobre el comportamiento textual o pragmático de estos elementos.

Parece, pues, bastante evidente que tengamos que pagar algún precio por su novedad. De hecho, la confusión se extiende desde la simple denominación de estas formas (expresiones, marcadores del discurso, partículas, apéndices, operadores discursivos, etc.) hasta su clasificación categorial ${ }^{2}$.

Aun siendo conscientes del riesgo que supone adentrarse en un terreno de investigación poco explorado como éste, presentamos el siguiente trabajo con la intención de ir llenando el ya mencionado vacío bibliográfico, que afecta sobre todo a los estudios monográficos centrados en determinadas formas. Los marcadores con función textual de «resumen», «conclusión» y «cierre» ${ }^{3}$ que hemos seleccionado - en resumen, resumen, en resumidas cuentas, en suma, total, en conclusión, conclusión, en fin, finalmente y por último- no han sido objeto de

Para el inglés, como exponente de este interés, y a título de ejemplo, valga citar la gramática de Randolph Quirk et alii 1985 (cfr. el capítulo 8 «The semantics and grammar of adverbials»). En relación con la lengua francesa, a lo largo de este artículo, se dará cuenta de algunas de las numerosas publicaciones sobre el tema (M. Schelling 1983; E. Roulet 1987; S. Stati 1990 , etc.).

2 Aunque son muchos los autores que han emprendido la díficil tarea de realizar una clasificación categorial de estos elementos, aquí vamos a pasar por alto esta cuestión. Para nosotros, lo importante no es encasillarlos dentro de una categoría determinada, sino señalar que su misión es poner en relación dos o más enunciados.

${ }^{3}$ Creo conveniente señalar que seguimos la distinción establecida por E. Coseriu 1992 entre «funciones de las lenguas» $\mathrm{y}$ «funciones textuales» (págs. 207-208). 
descripciones lingüísticas pormenorizadas, en lo que a la lengua española se refiere 4 .

\section{PROCEDENCIA DE LOS DATOS}

Los ejemplos que integran el corpus que se ha utilizado para la realización de este trabajo, tienen una doble procedencia. Por una parte, tenemos un corpus de lengua escrita ${ }^{5}$, cuyos testimonios provienen de artículos periodísticos, libros de texto y obras de carácter literario. Por otra parte, disponemos de testimonios de lengua oral, procedentes del corpus que se está elaborando en estos momentos en la Universidad de La Coruña ${ }^{6}$.

De este último hemos utilizado diez entrevistas ${ }^{7}$, de las cuales seis se realizaron a mujeres, tres a hombres, y una a un hombre y una mujer (matrimonio). Todos ellos tienen la residencia fijada en La Coruña.

Se han establecido tres variables sociales ${ }^{8}$ : el sexo (hombres y mujeres); la edad (segmentada en cuatro estratos: 15-24 años; 25-40 años; 41-59 años; 60 años en adelante); y el nivel de instrucción (alto, medio-alto, medio-bajo y bajo).

\section{CARACTERIZACION GRAMATICAL}

4 Podemos encontrar alguna referencia a estas unidades, además de en las obras lexicográficas, en los trabajos de Mª Luz Gutiérrez 1978; W. Beinhauer 1978; Ana Mª Vigara Tauste 1980; Catalina Fuentes 1987; Humberto Mederos 1987 y Antonio Briz 1993 y en prensa, pero de ningún modo se lleva a cabo un estudio exhaustivo de las mismas.

5 En realidad, éste es el que ha resultado nés productivo.

6 El proyecto de investigación para la formación de este corpus de lengua hablada está subvencionado por la Universidad de La Coruña, por la Xunta de Galicia y por la DGICYT.

7 Constituyen aproximadamente un total de siete horas de grabación.

8 Tanto el establecimiento de estas tres variables sociales como las convenciones de transcripción, puede que no coincidan con las que se establezcan cuando finalice la elaboración del proyecto al que pertenecen estos datos. Éstas han sido seleccionadas de manera provisional para nuestros fines más inmediatos.

Las convenciones de transcripción que se han utilizado son las siguentes:

E: entrevistador/a

E1, E2...: en el supuesto de que haya más de un entrevistador

$\mathrm{H}$ : hablante

H1, H2...: cuando aparece más de un hablante

... indican pausa o vacilación

() forma pronunciada

[ ] comentario no lingüístico o paralingüístico

\#nombre\#, \#lugar\# u otro \#dato\# omitido para preservar la confidencialidad. 


\subsection{Lexicalización}

La mayoría de estas formas comparten una serie de características que nos informan de que el proceso de lexicalización ha tenido lugar. No obstante, aunque dicho proceso de lexicalización se haya producido, podemos hablar de una diferencia de grado. Ésta es la razón que nos ha llevado al establecimiento de dos grupos.

Por un lado, los marcadores en resumen (o resumen), en fin, en conclusión, total, en suma, en resumidas cuentas $^{9}$ y por último están completamente lexicalizados: no varían aunque varíe el contexto, no se puede alterar el orden de los elementos, ni introducir nada entre ellos.

Por otro lado, tenemos la forma conclusión cuyo grado de lexicalización depende de la lengua funcional en que se encuentre. Puede aparecer tanto la forma conclusiones como la forma conclusión ${ }^{10}$.

Tras una revisión detenida del corpus, hemos comprobado la presencia de otros procedimientos, con un grado de fijeza distinto, que pueden desempeñar las funciones textuales de «resumen», «conclusión» y «cierre» en el discurso. Veamos, pues, algunos ejemplos:

(1) «Resumiendo, entonces: que si artísticamente se defiende, a cachos y por días, en RTVE, económicamente, el asunto anda un poco embrollado» (Antonio Nombela, El Ideal Gallego ${ }^{11}, 16.12 .91$, pág. 55) ${ }^{12}$.

(2) «Resumamos: acción, muertes aventuras, peripecias sentimentales, truculencias... Hay mucho, pues, en La verdad sobre el caso Savolta de remedo, de pastiche» (Vicente Tusón y Fernando Lázaro Carreter, Literatura española ${ }^{13}$, pág. 438).

(3) «La conclusión del cuestionario articulista es que: Las iglesias son empresas, y compiten entre sí en el espacio físico del mundo» (Horacio Carballal, EIG, 16.12.91, pág. 46).

(4) «Y para terminar, esta otra tremenda afirmación: Hay quien dice que ahora no es el momento de la disolución, que más adelante; no lo sé, lo que si sé es que no se puede estar mucho tiempo abrazado a un muerto» (Emilio Romero, La Voz de Galicia $^{14}, 11.12 .91$, pág. 9).

9 He podido escuchar en varias ocasiones la forma en resumidas, pero no puedo afirmar nada respecto de su uso y difusión porque las personas que lo pronunciaron eran miembros de una misma familia.

io Esta unidad, al igual que resumen, tiene unas características gráficas (suele aparecer a distinto nivel y con un tipo de letra diferente) que la convierten en una especie de titular, de rótulo, de Ilamada de atención de carácter didáctico.

11 En adelante, EIG.

12 El grado de lexicalización de esta forma es alto, ya que el genundio aparece utilizado como forma independiente.

13 En adelante, $L E$.

14 En adelante, $L V G$. 
(5) «Pero Volvamos a Antonio Carballo Tenorio para señalar, como final de estas líneas, que con su muerte se fue acaso el último representante de aquel periodismo de antaño que tan brillante papel realizó dentro de una profesión que no será nunca bien alabada por lo que supone de esfuerzo diario, de total entrega a los más altos ideales y de una vocación a toda prueba» (J, Naya Pérez, $L V G$, 15.12.91, pág. 42).

En consecuencia, no son los marcadores que venimos estudiando los únicos recursos válidos regulados idiomáticamente para expresar las funciones textuales mencionadas.

\subsection{Presencia / ausencia del marcador}

A mi modo de ver, los resultados que se obtengan tras el análisis que se realiza en este apartado son de crucial importancia, ya que si demostramos que la presencia del marcador no es pertinente, no tiene mucho sentido seguir adelante con este estudio. Sin embargo, llegados a este punto, se hace necesaria una precisión y es que, al hablar de la pertinencia de la presencia del marcador frente a su ausencia, conviene hacer una distinción entre lengua escrita y lengua oral, porque la situación en ambas modalidades no parece ser la misma.

Podemos afirmar con bastante certeza que en lengua escrita su presencia es siempre pertinente (dejamos al margen aquellos estilos en los que se intenta imitar la lengua coloquial). De tal modo que la supresión del marcador, cuando no produce una secuencia incoherente, lleva consigo la supresión de alguna de las funciones textuales que estudiamo ${ }^{15}$, dando lugar a un cambio de estilo, modificando la interpretación de la secuencia.

Obsérvense, por ejemplo, estos testimonios en los que la ausencia del marcador provoca la anulación de una función textual determinada:

(6a) En resumen, el comportamiento de los alumnos fue ejemplar.

(6b) $\{\varnothing\}$, el comportamiento de los dlumnos fue ejemplar.

(7a) «Total, que anda suelta por la geografía política gallega una nueva criatura que podría convertir a muchos James Deans gallegos en los «rebeldes con causa» del siglo XXI: el nacionalismo moderno» (J. González Méndez, $L V G, 23.12 .91$, pág. 6).

$(7 b) \ll\{\varnothing\}$ anda suelta por la geografía política gallega una nueva criatura que podría convertir a muchos James Deans gallegos en los «rebeldes con causa» del siglo XXI: el nacionalismo moderno».

(8a) «Conclusión: La obra se transforma en una peripecia que tiene como motivo central la venganza, en la que los actores no aciertan a recrear sus personajes, y donde el resultado final es una película de género bien resuelta, pero en la que el protagonista se pasa su papel chillando; donde la magnífica

is Asimismo la sustitución de un marcador por otro produce un cambio de perspectiva. 
Glenn Close no entiende nada del personaje que le han mandado interpretar. Sólo la locura de Ofelia adquiere verdadera entidad» (Travelling, $L V G, 7.12 .91$, pág. 28).

(8b) «\{Ø\} La obra se transforma en una peripecia que tiene como motivo central la venganza, en la que los actores no aciertan a recrear sus personajes, y donde el resultado final es una película de género bien resuelta, pero en la que el protagonista se pasa su papel chillando; donde la magnífica Glenn Close no entiende nada del personaje que le han mandado interpretar. Sólo la locura de Ofelia adquiere verdadera entidad».

En (6b), (7b) y (8b) la secuencia que introducía el marcador ya no se interpreta como un «resumen», un «resultado» o una «conclusión» de lo que se dijo anteriormente.

Una modificación en la interpretación del enunciado se produce en los casos que a continuación presentamos:

(9a) «Galicia, ni carece de un suelo rico, ni de primeras materias, ni tampoco de capital; fáltale, sí, educación agrícola, cultivo adecuado: en suma, inteligencia, arte» (F. Bermejo Martínez, El Correo Gallego ${ }^{16}, 12.12 .91$, pág. 45).

(9b) «Galicia, ni carece de un suelo rico, ni de primeras materias, ni tampoco de capital; fáltale, sí, educación agrícola, cultivo adecuado $\{\varnothing\}$ inteligencia, arte».

(10a) «Sin vías modernas de comunicación; con los peores accesos por carretera y ferrocarril de España y Portugal; con nuestros puertos maniatados por el centralismo administrativo; con los sectores pesquero y agrícola-ganadero abandonados al proceso de adhesión a la CEE, cuando no ofrecidos como contrapartida de otros intereses; con los más precarios equipamientos culturales y sanitarios; con la expoliación histórica de nuestros recursos naturales; con la reconversión industrial en términos relativos más brutal de España; con tanto abandono y marginación; en fin: sin inversión ni empleo, nos esperan horas difíciles» (V. Moro, $L V G, 7.12 .91$, pág. 9).

(10b) «Sin vías modernas de comunicación; con los peores accesos por carretera y ferrocarril de España y Portugal; con nuestros puertos maniatados por el centralismo administrativo; con los sectores pesquero y agrícola-ganadero abandonados al proceso de adhesión a la CEE, cuando no ofrecidos como contrapartida de otros intereses; con los más precarios equipamientos culturales y sanitarios; con la expoliación histórica de nuestros recursos naturales; con la reconversión industrial en términos relativos más brutal de España; con tanto abandono y marginación; $\{\varnothing\}$ sin inversión ni empleo, nos esperan horas difíciles».

Tanto en (9b) como en (10b) es posible una interpretación enumerativa.

16 En adelante, ECG. 
En el siguiente testimonio, sin la utilización de finalmente, no podemos saber que hay intención de cerrar una serie:

(11a) «La prueba del laberinto relata el viaje de un escritor a los escenarios de la vida de Jesús para escribir un libro sobre su figura. La acción arranca con el encargo editorial, y la primera parte revela cómo funciona a veces el negocio del libro. En la segunda empieza el vagabundeo: Palestina, Egipto, India... El protagonista registra sus experiencias en un diario y en unas cartas dirigidas a - iii!!! - Sánchez Dragó. Finalmente, en la tercera parte, se relata su viaje a la catedral de Chartres — centro del laberinto» (Javier Ortega, Gaceta Universitaria ${ }^{17}$, 22.3.93, pág. 20).

(11b) «La prueba del laberinto relata el viaje de un escritor a los escenarios de la vida de Jesús para escribir un libro sobre su figura. La acción arranca con el encargo editorial, y la primera parte revela cómo funciona a veces el negocio del libro. En la segunda empieza el vagabundeo: Palestina, Egipto, India... E1 protagonista registra sus experiencias en un diario y en unas cartas dirigidas a - iii!!! - Sánchez Dragó. $\{\varnothing\}$ en la tercera parte, se relata su viaje a la catedral de Chartres -centro del laberinto».

Ante una secuencia como (11b), no tendríamos por qué considerar que esta parte, la tercera, es la última del libro.

Por último, en (12a) el marcador aparece acompañando a una conjunción (a menudo estos elementos aparecen combinados con conjunciones):

(12a) «Es verdad también que mi aceptación ante el ofrecimiento de escribir este libro estaba acompañada por mi admiración al personaje en todo esto: la liquidación de la «guerra fía», que siempre puso en gravísimo riesgo de una guerra nuclear, con la colaboración y también iniciativa, primero de Reagan y después de Bush; el beneplácito para que los países del Este de Europa y de una Alemania, secuestrados por la Unión Soviética en función de famosos tratados con el mundo occidental, eligieran sus destinos políticos; $\mathrm{y}$, por último, la reforma o "perestroika» de su país en orden a un socialismo democrático desde sus viejas ideologías, y a un pluralismo generalizado para la política, la economía y la cultura. Gorbachov, por todo esto, es justo que figure en esa lista de personajes universales de este siglo» (Emilio Romero, $L V G, 27.12 .91$, pág. 12).

(12b) «Es verđad también que mi aceptación ante el ofrecimiento de escribir este libro estaba acompañada por mi admiración al personaje en todo esto: la liquidación de la «guerra fía», que siempre puso en gravísimo riesgo de una guerra nuclear, con la colaboración y también iniciativa, primero de Reagan y después de Bush; el beneplácito para que los países del Este de Europa y de una Alemania, secuestrados por la Unión Soviética en función de famosos tratados con el mundo occidental, eligieran sus destinos políticos; y $\{\varnothing\}$ la reforma $o$

17 En adelante, $G U$ 
«perestroika» de su país en orden a un socialismo democrático desde sus viejas ideologías, y a un pluralismo generalizado para la política, la economía y la cultura. Gorbachov, por todo esto, es justo que figure en esa lista de personajes universales de este siglo».

La función del marcador en (12a) es la de dar una orientación más explícita, esto es, precisar el sentido de la conexión indicada por la conjunción. La matización que proporciona el marcador desaparece en (12b). Como dice Catalina Fuentes 1987, la conjunción marca «la conexión sintáctica» y el marcador «la cohesión textual» (pág. 65) ${ }^{18}$.

En lengua oral, la situación es en cierto modo diferente, al estar dotada de una serie de recursos de los que está desprovista la lengua escrita. Entre otras cosas, contamos con determinados rasgos fónicos, que pueden ser índice de una interpretación determinada en ausencia de un marcador.

Por otro lado, en lengua oral no debemos olvidar la frecuente aparición de algunos de estos marcadores actuando como meros apoyos discursivos (por lo que se les asigna el calificativo de «expletivos» 0 «muletillas»). Ante la presencia de uno de esos elementos sí que podemos afirmar que, al menos desde el punto de vista del contenido semántico, la supresión del marcador es posible sin que por ello se obtenga un resultado inaceptable, ni se modifique la interpretación de una secuencia.

18 Se señala normalmente como característica de estas unidades su posibilidad de entrar en combinación con conjunciones; de hecho en nuestro corpus encontramos no pocos testimonios. Lo que hemos observado es un predominio de las combinaciones con la conjunción copulativa y y con la adversativa pero. A propósito de ellas dice Humberto Mederos 1988: 'El carácter muy general de las relaciones expresadas por $y$ y pero les permite combinarse con conectivos muy distintos' (pág. $215)$. Veamos algún ejemplo más con la conjunción copulativa $y$ :

- «La Policía habría recibido orden de encontrar al ex director desaparecido y, en suma, dejaríamos de ser los medios de comunicación los únicos que, de verdad, parecemos interesados por el caso» (F. Ramos, $E C G, 15.12 .91$, pág. 2).

- «Y, en fin, la larga enfermedad y la muerte de su hermanito, Luis, vendrá a sumarse a todo como un hecho decisivo que le conduce al escepticismo ante la ciencia y a las más negras ideas sobre la vida» ( $L E$, pág. 94).

Si tenemos en cuenta que en la gramática de Randolph Quirk 1985 se incluye a estos marcadores dentro del grupo de los sumativos («summative») y de los enumerativos («enumerative»), podemos entender por qué la combinación con la conjunción copulativa es tan frecuente, al ser ésta la conjunción que liga aditivamente elementos.

Entre los ejemplos con la adversativa pero tenemos casos como el siguiente:

- «-... ¡Pobre Florentinín, con lo sensible que él es, teniendo que trabajar para un público tan atrasadado y, como él dice, lleno de prejuicios! ¡Qué horror!

-Sí, verdaderamente. Pero, ien fin!, ahora va bien...

-Sí, isi le durase!» (La colmena, pág.123).

Si algo define a todos estos testimonios es la pertinencia de la presencia del marcador. 


\subsection{Tipo de relación sintáctica}

En la tradición gramatical española se viene hablando de «coordinación» y «subordinación», que son las dos maneras de interrelacionarse las dos proposiciones que forman parte de una «oración compuesta». De acuerdo con esta distinción, la coordinación es una relación 'que une términos sintácticamente equivalentes e independientes entre sî’ (F. Lázaro Carreter 1984, s.v. coordinación) y la subordinación es una relación 'que se establece entre dos (o más) oraciones en el seno de una oración compuesta, cuando una de ellas, llamada oración subordinada depende lógica y gramaticalmente de la otra llamada oración principal' (Ibidem, s.v. subordinación).

Pues bien, lo que ahora nos debemos preguntar es si estos elementos instauran entre los segmentos que conectan un tipo de relación sintáctica equivalente a las que se establecen en el marco de la oración. Podemos partir del hecho de que si hablamos de oración principal y subordinada, también podríamos hablar de «enunciado principal» $y$ «enunciado subordinado» ${ }^{19}$. Así, por ejemplo, pensemos en el tipo de resumen que se sitúa al final de una lección; en este caso la comparación es posible, porque el segmento introducido por el marcador en resumen muestra una dependencia con respecto a lo anterior. Sin embargo, no podemos decir lo mismo de en conclusión ya que en muchos casos, sobre todo con un valor próximo a en consecuencia, nos encontramos con una relación de interdependencia.

En realidad, es una cuestión muy difícil de resolver y no pretendemos llegar aquí a ninguna solución. De cualquier forma, creo interesante mencionar lo que dice Sorin Stati 1990 a este respecto. Defiende que ciertas relaciones transoracionales son el equivalente de ciertas relaciones sintácticas oracionales al compartir el mismo sentido. $Y$ aunque esta equivalencia no justifica la etiqueta de «relación gramatical», termina diciendo que 'il y a des indices convaincants qui plaident en ce sens, de sorte qu' en fin de compte - et avec beaucoup de réserves et limitations prudentes- la légitimité de la dimension grammaticale des relations transphrastiques nous semble une thèse soutenable? (pág. 138).

Este autor presenta una nómina de relaciones sintácticas bastante amplia ${ }^{20}$. Algunos de los marcadores que aquí se analizan estarían dentro de lo que él llama relación sintáctica de «reformulación», y otros dentro de la de «consecuencia/

19 Así, Eddy Roulet 1987, entre otros, define a la reformulación como una 'subordination rétroactive d'un mouvement discursif, éventuellement d'un implicite, à une nouvelle intervention principale, du fait d'un changement de perspective énonciative' (pág. 111).

20 Establece siete tipos de relación «transphrastique»: «coordination», «reformulation», «explication, exemplification, spécification», «causale», «chronologique», «conséquence/conclusion» $\mathrm{y}$ «subordonnées isolées». 
conclusión». La primera, que se produce tanto entre oraciones como en el interior de las mismas, no la consideran las gramáticas como una relación sintáctica. En cuanto al sentido, se parece a una de las acepciones de la aposición: ' $D$ ' habitude, les relata sont quasi synonymes ou en léger contraste; leur ordre est fixe' (pág. 142). Habla de «orden fijo» porque la reformulación tiene que venir después. Con respecto a la segunda de estas relaciones, dice que no hay acuerdo sobre si es coordinación o subordinación, 'mais la majorité des grammaires parlent de coordination' (pág. 150). De todos modos, debemos tomar con precauciones la clasificación que realiza S. Stati, ya que, a nuestro parecer, confunde el sentido con la relación sintáctica.

Como vemos, el marco de la gramática tradicional es insuficiente para dar cuenta de las relaciones sintácticas que instauran estos elementos. Las limitaciones son comprensibles teniendo en cuenta las restricciones que impone el considerar como unidad superior en el análisis gramatical a la oración. Pensemos, además, que estamos en un nivel superior, el texto, con unas características propias y definitorias.

En este sentido, para concluir, podemos aplicar a nuestros marcadores lo que M. Casado Velarde 1991 dice a propósito de los marcadores de «explicación»: 'instaurarían relaciones sintagmáticas de concatenación. Sirven para colgar un inciso a determinados segmentos de la cadena hablada' (pág. 102) ${ }^{21}$.

\subsection{Unidades independientes}

A menudo se señala como un rasgo definitorio de los marcadores discursivos el hecho de que constituyen siempre unidades fónicas independientes, de ahí que vayan separados de las secuencias adyacentes por pausas. Estas pausas quedan representadas gráficamente en la escritura a través del empleo de dos puntos, coma o punto y coma 22 :

(13) «En resumen: el artículo de Charolles aporta una regla de coherencia y otra de congruencia» (A. Vilarnovo, 1991, pág. 138).

Entre los marcadores que incluye en la reformulación están (señalo sólo los que tienen más relación con los que estudiamos): enfin, au fond, somme toute, en somme, en fin de compte, finalement, en définitive...(Stati 1990:142)

Los pertenecientes al grupo de consecuencia/conclusión son: en conséquence, par conséquent, donc, etc. (pág. 150).

21 M. Casado Velarde 1991 sigus a E. Coseriu 1981: 'de una manera muy general las relaciones sintagmáticas en el nivel del texto sólo pueden ser de tres clases: anticipación, anáfora y concatenación' (cfr. págs. 174-176).

22 Incluso tenemos documentado algún caso en que el marcador se sitúa entre guiones:

«(...) Pero, a partir de esa figura real, Luces de bohemia cobra unas dimensiones que trasciende ampliamente la anécdota del fracaso y la muerte de un escritor - en suma-mediocre» ( $L E$, pág. 197). 
(14) «Todo parece preparado, en suma, para que el año 1992 comience con un cambio de líder a la cabeza de la clasificación bancaria española» (Primo González, $L V G, 27.12 .91$, pág. 50)».

(15) «En fin, un concierto gris» (Ramiro Cartelle, $L V G, 15.12 .91$, pág. 40).

(16) «Total, que anda suelta por la geografía política gallega una nueva criatura que podría convertir a muchos James Deans gallegos en los «rebeldes con causa» del siglo XXI: el nacionalismo moderno» (J. González Méndez, $L V G, 23.12 .91$, pág. 6).

(17) «Conclusión: si naces perro te conviene ser de raza, y si eres extranjero, mejor que seas millonario» (Cristina Peri Rossi, $L V G, 19.12 .91$, pág. 11).

(18) «Finalmente, aunque su esperanza en una sociedad mejor fuese cada día más pequeña, sintió siempre -él, tan pacífico— una gran añoranza de acción» (LE, pág. 88).

(19) «Por último, en el caso intervienen agentes especiales, una unidad similar a los famosos Intocables de Eliot Ness» ( $L V G$, Leoncio González, 27.12.91, pág. 24).

La representación entre pausas es una constante en lengua escrita, pero no es menos cierto que en lengua oral estas pausas en muchos casos no se realizan. Cuando manejemos el corpus de lengua oral, respetaremos en la escritura este hecho.

De cualquier modo, y a falta de otros recursos, en lengua escrita las pausas son un elemento pertinente en caso de homofonía. Así, la interpretación de total en este texto variará en función de la presencia o no de una pausa antes:

(20) «Cuando Traveller le presentó a Talita en el puerto, tan ridícula con ese gato en la canasta y un aire entre amable y Alida Valli, volvió a sentir que ciertas remotas semejanzas condensaban bruscamente un falso parecido total, como si de su memoria aparentemente tan bien compartimentada se arrancara de golpe un ectoplasma capaz de habitar y contemplar otro cuerpo y otra cara, de mirarlo desde fuera con una mirada que él había creído reservada para siempre a los recuerdos» (Julio Cortázar, Rayuela $a^{23}$, pág. 275).

(21) «Cuando Traveller le presentó a Talita en el puerto, tan ridícula con ese gato en la canasta y un aire entre amable y Alida Valli, volvió a sentir que ciertas remotas semejanzas condensaban bruscamente un falso parecido, total, como si de su memoria aparentemente tan bien compartimentada se arrancara de golpe un ectoplasma capaz de habitar y contemplar otro cuerpo y otra cara, de mirarlo desde fuera con una mirada que él había creído reservada para siempre a los recuerdos».

23 En adelante, $R$. 
Véanse además estos otros ejemplos construidos al efecto:

(22) Todo esto viene, en resumen, al final / Todo esto viene en resumen al final.

(23) Te tengo, en suma, estima / Te tengo en suma estima.

(24) Conclusión: es una palabra de difícil significado/ Conclusión es una palabra de difícil significado.

Las pausas en estos casos son la marca formal de la función lingüística que realizan los marcadores.

\subsection{Colocación de los marcadores}

Los marcadores presentan una doble adherencia (Stati), anafórica y catafórica, esto es, remiten a lo que se dijo anteriormente y a lo que se va a decir a continuación. De ahí que no sea posible la aparición de secuencias « $\{\varnothing\}+$ marcador»o «marcador $+\{\varnothing\} » »^{24}$.

Esto no impide que entre el marcador y el enunciado que introduce pueda intercalarse alguna secuencia como elemento parentético. Véanse estos dos ejemplos ${ }^{25}$ :

(25) En resumidas cuentas, como habrás podido comprobar, no pienso acercarme a su casa hasta que me lo pida.

(26) Total que, como tú bien decías, no pude conseguir el préstamo.

Dentro de este apartado vamos a diferenciar:

A. La colocación del marcador con respecto a la totalidad del texto.

B. La colocación del marcador en el marco del enunciado.

\section{A. Colocación en el texto}

En resumen (o resumen), en suma, en fin, total, en conclusión (o conclusión), finalmente y por último pueden hacer referencia a un texto entero, a un fragmento textual con cierta autonomía, a un párrafo, a una oración, o incluso a una unidad menor ${ }^{26}$, dependiendo de lo que se quiera «resumir», «concluir» o «finalizar».

Ninguno de ellos puede aparecer en posición inicial absoluta, salvo que se pretenda conseguir una determinada finalidad expresiva. Así, en nuestro corpus

24 Como veremos más adelante, hay casos en que el marcador no va introduciendo una secuencia, sino que va seguide de silencio. Pero, en cualquier caso, no se podría hablar de vacío discursivo ya que va a ser la presuposición la que se encargue de llenarlo.

25 Esto ocurre también con los restantes marcadores.

26 Véase, por ejemplo, en el apartado de los valores de los marcadores el correspondiente a en fin de rectificación. 
tenemos un artículo que empieza con un total, que se explica si tenemos en cuenta que este tipo de artículos va dirigido a un público que lee habitualmente el periódico y está familiarizado con el tema que se va a tratar. Con él se crea un efecto de solidaridad con el lector, se considera que comparte una experiencia común con el articulista. El lector debe sobrentender el «contexto» del artículo, o sea, la noticia del momento a la que hace referencia:

(27) «Total, que todo aquello, la hoz y el martillo, el coro sobrecogedor de La Internacional, la dictadura del proletariado, una escena de «Octubre», el eco lejano de los cañones «Aurora», un grito de Lenin intentando despertar la historia, un poltergeist de los que dejó Stalin a medio camino entre el más allá y la Tierra, un ladrido de «Laika» navegando por el espacio, un zapato de Kruchev resonando eternamente en un escaño de la ONU, todo aquello a lo que hemos llamado durante setenta y cuatro años Unión de Repúblicas Socialistas Soviéticas, resulta que cabría en el dichoso «maletín nuclear» que acaba de entregarle el ex-camarada Gorbi al ex-camarada Boris» (J. González Méndez ${ }^{27}$, $L V G, 27.12 .91$, pág. 8).

Por lo demás, todos estos marcadores pueden aparecer en posición media y final de un texto.

\section{B. Colocación en el enunciado}

Podemos establecer dos grupos:

b.1. Formas que presentan movilidad oracional sin restricciones: los marcadores en resumen, en suma, en fin, en conclusión y finalmente pueden ocupar posición inicial, media y final $^{28}$. Si bien tenemos que advertir que se observa una preferencia por la posición inicial:

(28) «En resumen, la estructura de La verdad sobre el caso Savolta supone un gradual deslizamiento desde las formas más complejas de la narrativa actual hasta viejas (o «marginales») formas de contar, intencionadamente resucitadas» ( $L E$, pág. 436).

(29) «La octava, en resumen, es un excelente ejemplo del estilo de Góngora» (Fernando Lázaro Carreter y Evaristo Correa Calderón, Cómo se comenta un texto literario ${ }^{29}$, pág. 125).

(30) «Ahora, diga usted - siguió diciendo Andrés-, qué es lo que usted quiere, en resumen ${ }^{30} »$ (Pio Baroja, El árbol de la ciencia, pág. 119).

\footnotetext{
${ }^{27}$ Este autor suele cultivar, en sus colaboraciones periodísticas, un estilo confianzudo, con abundantes rasgos coloquiales.

${ }_{28}$ La aparición en posición final es más frecuente en la lengua culta que en la coloquial.

29 En adelante, CCTL.

30 El mismo ejemplo vale para el marcador en resumidas cuentas.
} 
(31) «En suma, que el trío real está asediado por una competencia bastante desleal y por niños como este Angelito con instinto de «broker» prematuro» (Carlos Luis Rodríguez, $L V G, 26.12 .91$, påg. 8).

(32) «La Policia habria recibido orden de encontrar al ex director desaparecido $\mathrm{y}$, en suma, dejaríamos de ser los medios de comunicación los únicos que, de verdad, parecemos interesados por el caso» (Fernando Ramos, ECG, 15.12.91, pág. 2).

(33) «De hecho, si sabemos que ha de quedar constancia (magnetofónica, por ejemplo) de nuestras palabras (y de la entonación, etc.), si van a poder ser repetidamente comprobadas, analizadas, criticadas, seremos más cuidadosos con lo que decimos y con cómo lo decimos: menos espontáneos, en suma» (Ana Ma Vigara Tauste, Morfosintaxis del español coloquial, 1992, pág. 43).

(34) «En fin, se empieza por cargar el acento en una comisaría cada cien metros y se acaba perdiendo toda noción de un problema del que poco se arregla con la represión en cabeza» (Juan José Moralejo Álvarez, $L V G, 12.12 .91$, pág.11).

(35) «La democracia, en fin, es lo único que tenemos pero es también el retrato fehaciente y cruel de nuestras peores miserias» (Pedro Villalar, ECG, 25.12.91, pág. 3).

(36) «Por todo ello, no extraña que se les tilde de «herméticos», de «abstractos», de «fríos», de «deshumanizados, en fin» ( $L E$, pág. 276).

(37) «En conclusión, desde nuestro punto de vista, los enlaces conjuntivos forman un paradigma homogéneo con comportamiento único cuyas características vamos a estudiar» (Catalina Fuentes R., 1987, pág. 50).

(38) Desde nuestro punto de vista, los enlaces conjuntivos, en conclusión, forman un paradigma homogéneo con comportamiento único cuyas características vamos a estudiar.

(39) Después de conocer todos esos detalles, qué vas a hacer, en conclusión.

(40) «Finalmente, en la cárcel compone la mayor parte del Cancionero y romancero de ausencias (1938-1941)" (LE, pảg. 490).

(41) Es, finalmente, su gran sentido del humor el que hace que sea un ser encantador.

(42) No voy a la excursión, finalmente.

Cuando estos marcadores van en posición media, es interesante observar en qué lugares dentro de la secuencia pueden introducirse. A modo de ejemplo véanse los siguientes casos:

- Sujeto + marcador + verbo:

«La octava, \{MARCADOR $\}^{31}$, es un excelente ejemplo del estilo de Góngora» (cfr. ejemplo 29).

31 Sustitúyase en todos los casos por cualquiera de los marcadores anteriormente señalados que pueden ocupar posición media. 
adjetivo):

- Núcleo + marcador + adyacente (sintagma preposicional o sintagma

«Amigo, \{MARCADOR ${ }^{32}$, de muchos hombres cuya opinión importa a la hora de hablar de América y a los que visita regularmente» (Carlos G. Reigosa, $L V G, 7.12 .91$, pág. 9).

Es una mujer, $\{$ MARCADOR $\}$, perfecta.

\section{- Verbo + marcador + complemento:}

«Lo que quiere decir, \{MARCADOR $\}^{33}$, que el texto deja de considerarse como una mera unidad de orden superior, pero equiparable a la frase u otras unidades inferiores del sistema de la lengua» (E. Bernárdez, Introducción a la Lingüística del texto, pág. 39)

- Verbo auxiliar + marcador + verbo auxiliado (en las perífrasis verbales):

No voy, \{MARCADOR \}, a continuar con esta farsa.

Creemos que a través de estos ejemplos se deja constancia de la variedad de posiciones en los que se puede intercalar un marcador dentro de una secuencia.

b.2. Formas que presentan restricciones respecto a su colocación en el enunciado: dentro de este segundo grupo tenemos que incluir marcadores como por último, total, resumen y conclusión. A su vez, dentro de este grupo, cabe realizar una diferenciación, ya que el primero de los elementos aquí señalados sólo tiene prohibida la posición final ${ }^{34}$. En cambio, los tres últimos únicamente pueden aparecer al principio del enunciado que introducen (resumen y conclusión seguidos de una pausa más fuerte que normalmente se representa en la escritura por dos puntos $)^{35}$ :

(43) «Por último, y desde la perspectiva que nos interesa en este curso, cabe observar que las ideas examinadas cuentan con importantes antecedentes en la literatura española de los años 30» ( $L E$, pág. 341).

(44) «Pueden, por último, aparecer a un tiempo mismo con varios matices las operaciones del alma» (RAE, Gramática de la lengua española, 1931, pág. 124).

$(45)^{*}$ Pueden aparecer a un tiempo mismo con varios matices las operaciones del alma, por último.

32 Original en suma.

33 Original en resumidas cuentas.

34 Hay ocasiones en que la aparición de este marcador en posición final podría dar lugar a una secuencia aceptable; principalmente cuando acompaña a un enunciado de extensión limitada:

- Mencionaremos a la tercera de estas especies, por último.

Por tanto, todo parece indicar que su aceptabilidad en esta posición dependerá de la magnitud del segmento (vid. ejemplo 45).

35 Cfr. nota 10. 
(46a) Total, un desastre.

(46b)* Un desastre, total.

(46c)* Una situación, total, desastrosa.

(47a) Conclusión: La situación económica gallega está atravesando momentos difíciles.

(47b)* La situación económica gallega está atravesando momentos difíciles, conclusión.

(47c)* La situación económica gallega, conclusión, está atravesando momentos difíciles.

(48a) Resumen: la situación económica de estも-país es insostenible.

(48b)* La situación económica de este país, resumen, es insostenible.

(48c)* La situación económica de este país es insostenible, resumen.

Vemos que en (46a) se presenta una valoración de algo dicho anteriormente. En cambio, al situar total en posición final, correría el riesgo - aun con la pausa fónica-de ser interpretado como un adjetivo que modifica a «desastre»; ya no funcionaría como marcador textual.

\subsection{La forma que}

Hay ocasiones en que estas unidades van seguidas de la forma que, y otras en que no. La utilización de un marcador con que exige la presencia de una forma verbal en el enunciado que introduce.

Cuando aparece este que, no siempre es posible determinar si forma parte del marcador discursivo. A veces, lo único que hace es repetir el marcador de hipotaxis del primer segmento

La aparición de un verbo subordinante explícito en el enunciado, es un factor que influye en el grado de pertinencia de la presencia de esta forma. Así, cuando no contamos con dicho verbo subordinante, la supresión del segmento que no conlleva alteraciones sustanciales en el contenido de la secuencia:

(49) En resumen, que este asunto no tiene solución.

(49a) En resumen, este asunto no tiene solución

(50) En suma, que no sé qué hacer.

(50a) En suma, no sé qué hacer.

(51) En fin, que si no fuese por lo que quiero a mi hermano, no hubiese dicho la verdad.

(51a) En fin, si no fuese por lo que quiero a mi hermano, no hubiese dicho la verdad.

(52) «Total que te instalaste como un bacán. Chapeau, mon vieux. Espero que no me habrán tirado la yerba a la basura» $(R \text {, pág. } 170)^{36}$.

36 No es frecuente que en lengua escrita aparezcan casos como éste, sin una coma entre el 
(52a) «Total, te instalaste como un bacán. Chapeau, mon vieux. Espero que no me habrán tirado la yerba a la basura.

(53) En conclusión, que no iré aunque me lo pida.

(53a) En conclusión, no iré aunque me lo pida.

En todos estos casos se nota una dependencia de un verbo de lengua presente en el contexto de la enunciación.

Sin embargo, cuando en la secuencia existe un verbo subordinante explícito, la presencia de la forma que es siempre pertinente:

(54) «Nunca hubiera creído. Me pareció que usted... En fin, que Pola pasaría como algunas otras. Porque también habría que nombrar a Françoise, por ejemplo» $(R$, pág.134).

(55) «El primer culpable soy yo, porque no quería que Talita creyera... En fin, que te dejaba de lado en este asunto para librarme de vos. Cuestión de amor propio te das cuenta» ( $R$, págs. 289-290).

(56) Pensaba que tenías que estudiar, que te habían castigado, que tenías que hacer todo lo de casa, en conclusión, que no te dejaban salir.

(57) Pues dile que vaya a su casa, que pregunte por él y que le pida disculpas; en resumen, que aprenda a ser persona.

(58) Comentó que no se lo merecía, que era demasiado para él, en suma, que no podía aceptar el regalo que le habíamos enviado.

(59) Pregúntale qué hacía en mi casa, qué quería de mí, qué traía en la mano, en fin, qué se propone.

En todos estos ejemplos la ausencia del que tras el marcador provocaría secuencias inaceptables $(54,55,56$ y 59$)$ o interpretables de manera diferente (57 y 58); así, en (57) su desaparición produciría un cambio en el valor de la forma verbal, que pasaría a indicar una orden.

\section{VALORES Y EMPLEOS DISCURSIVOS DE LOS MARCADORES ESTUDIADOS}

Antes de adentrarnos en el estudio de los valores y usos de estas formas, debemos anticipar que la proximidad entre las funciones textuales de «resumen», «conclusión» $y$ «cierre» — próximas a su vez a la de «consecuencia»-, provoca

marcador y el que. De hecho, es un fenómeno constatado sólo en los ejemplos de este autor (J. Cortázar). En este sentido, refleja con bastante fidelidad lo que ocurre en lengua oral, donde lo normal es que no se haga la pausa (cuando utilicemos el corpus de lengua oral reflejaremos este hecho en la escritura). 
que los elementos encargados de desempeñar dichas funciones puedan coincidir en sus empleos discursivos en muchos contextos. Esta coincidencia puede llevarnos a interpretar estas formas como sinónimas ${ }^{37}$. Sin embargo, cada uno de estos marcadores apunta a un valor fundamental específico que parece derivar del contenido semántico de los mismos, contenido que perdura a pesar del proceso de gramaticalización al que están sometidos. Podemos concluir con Mª Antonia Martín Zorraquino 1988 que 'el significado (valor semántico) de los signos orienta su capacidad pragmática —y no al revés- (al menos para las partículas)' (pág. 286).

Por otro lado, nuestra intención en este apartado no es, ni mucho menos, dar una lista de todos los usos discursivos posibles de estas unidades. El hecho de trabajar con un corpus determinado impone ciertas restricciones. Además, si hay algo que caracteriza a estos elementos es su multifuncionalidad. En realidad, ésta obedece a factores pragmáticos. En última instancia es el hablante el que fija la interpretación de un marcador en un determinado contexto.

No quiero cerrar esta breve introducción, sin referirme a los aspectos suprasegmentales, ya que éstos desempeñan un papel importante a la hora de delimitar los distintos empleos discursivos que un marcador puede tener, de tal modo que el sentido puede matizarse por medio de la entonación: tono ascendente, descendente o en suspensión ${ }^{38}$. Acompañando a las particularidades entonativas, que les imprime el hablante al emitirlos, también nos encontramos con fenómenos paralingüísticos como pueden ser los gestos. Así por ejemplo, a través de estos últimos se expresan muchas veces los matices de resignación.

37 Veremos que en la tradición lexicográfica española es una constante la consideración de estas formas como sinónimas. Resulta curioso revisar los diccionarios de sinónimos. En ellos observamos que unos términos remiten a otros. Examinemos algunos ejemplos procedentes del Diccionario Manual de Sinónimos y Antónimos (1991):

«En conclusión. Én suma, por último, finalmente, en definitiva» (s.v. conclusión).

«Finalmente. En suma, por último, en conclusión» (s.v. finalmente).

«En suma. En definitiva, por último, finalmente, en conclusión» (s.v. suma).

Esta situación no es exclusiva de la lengua española. Así, a propósito de los «connecteurs reformulatifs» del francés, Eddy Roulet 1987 dice: 'la plupart des reformulatifs sont présentés par les dictionnaires comme des synonymes' (pág. 117). Este hecho lo pudimos comprobar, a la hora de buscar el equivalente castellano de las formas francesas. Por ejemplo, bajo la voz enfin un diccionario bilingüe nos remite a formas tan variadas como: por último, al fin, por fin, en una palabra, en fin, es decir, para abreviar (diccionario Larousse, 1987, s.v. enfin). Lo mismo ocurre con bref, en somme, au fond, etc.

38 Un requisito imprescindible para llevar a cabo un estudio riguroso de la entonación de estos marcadores, sería disponer de testimonios de cada uno de ellos en el corpus de lengua oral; pero éste sólo nos ha proporcionado testimonios de total y de en fin. Sin embargo, podemos decir, apelando a nuestra experiencia de hablantes, que nomalmente terminan con semicadencia. De cualquier forma, a la hora de abordar el estudio de los empleos discursivos de los dos marcadores citados anteriormente, señalaremos, cuando sea pertinente, la pronunciación que les corresponde. 


\subsection{En resumen y en suma}

La tradición lexicográfica presenta a estas dos formas como sinónimas. Así, el DRAE (1992) dice a propósito de en resumen 'resumiendo, recapitulando' (s.v. resumen); y con respecto a en suma 'en resumen'. A la anterior definición de en resumen el DUE (1966-1967) añade que 'se emplea para exponer la consecuencia a la que se llega después de un razonamiento, una discusión, etc.' (s.v. resumen). El mismo valor consecutivo se lo atribuye a en suma: 'expresión con que se introduce la exposición de una consecuencia o resumen de lo ya dicho' (s.v. suma).

Ciertamente, los empleos discursivos de estas dos piezas léxicas están bastante próximos ${ }^{39}$. Ambas tienen una función común que es la de reformulación: tras la aparición de una primera formulación de un enunciado, estos elementos introducen otro, de menor extensión en principio, que engloba al primero y lo subordina retroactivamente ${ }^{40}$. Por tanto, la relación entre la secuencia enunciada y su reformulación es de reformulación recapitulativa o sintética. El uso del marcador da instrucciones indicando que el último enunciado se debe interpretar como una síntesis. De ahí que sea un instrumento adecuado en las enumeraciones, cuando por razones de «economía lingüística» se cierra una enumeración, englobando con el segmento que introducen lo citado en la secuencia anterior:

(60) «Íntimo amigo del fallecido general Torrijos. Íntimo amigo del resistente Fidel Castro. Íntimo amigo del mexicano Salinas de Gortari, del venezolano Carlos Andrés Pérez y del colombiano César Gaviria. Íntimo amigo de Felipe González. Cada día más amigo de un Henry Kissinger que ha cambiado radicalmente su forma de mirar hacia el Sur de los EEUU. Amigo, en suma, de muchos hombres cuya opinión importa a la hora de hablar de América y a los que visita regularmente...» (Carlos G. Reigosa, $L V G, 7.12 .91$, pág. 9).

Podemos hablar de dos tipos de I eformulación recapitulativa o de recapitulación, sin más ${ }^{41}$ :

39 Podría decirse que el valor general del marcador en suma - y permítaseme expresarlo en términos matemáticos- es la presentación del «resultado» de la «suma» de lo que se dijo anteriormente. Por tanto, tendríamos que hablar de «resultado» frente a «síntesis» (en resumen). Siguiendo este razonamiento, al hablar de resultado, se podría, en principio, postular que la extensión de las secuencias que introduce no presenta restricciones, restricciones que afectan a en resumen (al menos en lengua escrita). Si este hecho se cumpliese, sería una de las diferencias de empleo de estas dos formas. Sin embargo, hemos podido comprobar en el corpus que esta distinción no funciona, y los enunciados que introduce en suma tienen una extensión similar a los que introduce en resumen. En todo caso, el rasgo diferencial habría que buscarlo en la lengua funcional, ya que en suma pertenece a una lengua funcional cuidada, culta.

40 A propósito de en somme, Corinne Rossari 1990 dice (llama p al enunciado que precede al marcador y $q$ al enunciado que introduce): '(...) avec un connecteur reformulatif comme en somme, le locuteur indique qu' il tire une synthèse de $p$, synthèse qu' il énonce en $q$. Les instructions relatives à en somme, à savoir, sommairement, «tirer une synthèse de», concernent donc p' (pág. 346).

41 Soy consciente de que para la total comprensión de estos ejemplos, y para así poder verificar la pertinencia de esta clasificación, sería necesaria la presentación del contexto dentro del 
A) Recapitulación condensadora (objetiva): se vuelve sobre la primera formulación de un enunciado (se entiende que éste puede ser de distinta extensión, capítulo, párrafo, etc.) con el fin de extraer lo esencial. En este primer tipo no se cuestiona la primera formulación en lo que respecta al contenido, sino que se limita a presentar una expresión más condensada ${ }^{42}$.

Entre los ejemplos más característicos del primer tipo están los resúmenes de la prosa didáctica:

(61) «En resumen, la estructura de La verdad sobre el caso Savolta supone un gradual deslizamiento desde las formas más complejas de la narrativa actual hasta viejas ( 0 «marginales») formas de contar, intencionadamente resucitadas. Se une así el placer de lo nuevo y de lo viejo. $\mathrm{Y}$ el autor ha buscado, como decimos, la complicidad del lector en diversos niveles» ( $L E$, pág. 436).

(62) «En suma, Cela no ha dejado de renovarse, rivalizando con escritores más jóvenes en los caminos de la experimentación» ( $L E$, pág. 376$)$.

B) Recapitulación valorativa o evaluativa (subjetiva) ${ }^{43}$ : se vuelve sobre el enunciado previo pero, además de la intención de abreviar, puede estar presente la de completar o clarificar lo dicho anteriormente. Hace referencia a un punto

cual se inscriben; pero como en la mayor parte de los casos se refieren a un texto entero, y no precisamente breve, es imposible dejar constancia del citado contexto (lo mismo sucede con otras formas que aquí se estudian).

42 Aquí habría que situar los empleos que se dan en lengua oral (normalmente coloquial, aunque también pueden aparecer en lengua escrita), en los que el hablante al introducir una de estas formas, se refiere a algo que tiene en mente pero que no ha sido expresado. Esto es, se omite la primera formulación:

A: ¿Qué te dijo el médico?

B: En resumidas cuentas, me dijo que tenía que dejar de fumar.

En realidad este empleo está a medio camino entre este tipo de recapitulación (A) y la siguiente (B). Por una parte, se hace una síntesis de lo enunciado, en este caso por el médico (objetividad), pero a su vez el hablante destaca de aquello que le dijo el médico lo que considera más importante, lo que realmente le interesa (subjetividad). Posiblemente también aquí subyace la intención de facilitar la tarea comprensiva al destinatario.

43 Dentro de este apartado habría que situar el uso de estos marcadores en las entrevistas, en la conversación ordinaria, etc. Pongamos un ejemplo referido a las entrevistas. En este sentido, podemos decir que a través de un enunciado introducido por en suma o en resumen el entrevistador puede hacer decir al entrevistado algo que jamás hubiese querido expresar. En principio, al utilizar uno de estos marcadores el entrevistador indica que la interpretación que se desprende de la intervención del entrevistado consiste en una pura síntesis, mientras que, en realidad, está sacando sus propias conclusiones. Si este último - el entrevistado- no muestra desacuerdo, significa que acepta como consistente esa versión condensada de su propio discurso:

Entrevistado: La situación del cine en España no es buena. Reconozco que hay actores que saben realizar su trabajo, pero el mayor problema es que no hay dinero.

Entrevistador: En resumen, lo que tú me intentas decir es que no volverás a hacer cine en España, ¿no?

Este mismo empleo es posible con otros marcadores que puedan reformular en un momento dado lo dicho en el primer enunciado (total, en conclusión, en fin, etc.): 
de vista no expresado en el contexto inmediato. Esto es, puede reducir a otros términos lo que se dijo en fases precedentes ${ }^{44}$. En los testimonios que caen dentro de este tipo de recapitulación se observa una aproximación a los valores consecutivos $^{45}$ :

(63) «La cumbre de Maastricht ha terminado con un saldo positivo. El nuevo Tratado de la Unión Europea será redactado y firmado en los primeros meses de 1992. La moneda única y el banco Central serán realidad en los últimos años de! siglo (...). En resumen, unas jornadas históricas» (José María de Areilza, LVG, 12.12.91, pág. 11).

(64) «En suma, el Parlamento gallego cumple su primera década aquejado de los mismos achaques que sus hermanos de todo el mundo. Se le estudia, se le mima, se le dota de amplio y bello edificio, pero no es el rey del mambo institucional sino un bailarín acompañante que díficilmente sigue el ritmo marcado por los Gobicrnos. En esto Galicia no es diferente» (C. Luis Rodríguez, $L V G, 11.12 .91$, pág. 10).

Quedan dos unidades que habría que incluir dentro de este apartado: resumen y en resumidas cuenlas. Sus empleos discursivos son los señalados más arriba. Como ya hemos dicho, resumen se diferencia de las anteriores por la ausencia de movilidad oracional, que lo hace ocupar siempre una posición fija. En resumidas cuentas es una forma que en la lengua coloquial va ganando terreno a la forma más tradicional en resumen. Veamos un par de ejemplos (el primero pertenece a

A: Cuando llcgamos no había nadic, la casa estaba muy vieja, no tenía piscina, tampoco cancha de tenis. Para colmo de males, llovió durante una semana.

\section{B: Tolal, que fue un desastre de viaje, ino?}

$\Lambda$ : Cuando llegamos, ya había preparado la cena, tenía la casa reluciente, la mesa ya estaba puesta y había planchado toda la ropa.

B: En conclusión, que no le habéis hecho nada, ¿verdad?

A: No tengo ropa bucna para ir a esa fiesta, mi padre no pucde llevarme, además no creo gue mi madre me levanie el castigo.

B: En fin, que no vas a venir.

44 La introducción de una valoración presupone muchas veces una norma de valoración común a todos los interlocutores, según la cual se considera que puede haber acuerdo con respecio al juicio emitido en el enunciado. Así, después de hablar de unas sesiones de cierta impontancia para el futuro de España se dice:

«En resumen, unas jornadas históricas» (ejemplo 63).

15 Fn alguna ocasión la sustitución de en resumen o en suma por en consecuencia sc podría aceptar. Cuando digo en consecuencia, me refiero también a todas aquellas piezas léxicas que puedan cumplir la función textual «consecuencia» (pues, por tanto, por lo tanto, elc.). Pero tengamos presente que, aunque esta sustitución se pueda considerar aceptable, la intención del hablante parece variar según utilice un marcador u otro. Por otra parte, creo que cualquier sustitución que se realice implica siempre un cambio, mayor o menor, en la secuencia. Esto incluso sucede con los marcadores que tienen un valor común, ya que la sinonimia «total» prácticamente no existe. 
lo que dimos en llamar recapitulación condensadora y el segundo, a la recapitulación evaluativa):

(65) «Resumen

Como recapitulación, el fragmento de «Azorín» revela una evidente unidad en sus tres componentes. Siendo la intención del autor describir las sensaciones visuales y auditivas de su despertar en Esquivias, a ellas se limita, en ellas concentra su invención. Como ese despertar se ha hecho en dos momentos, a cada uno dedica un parágrafo» (Fernando Lázaro Carreter y Vicente Tusón, Curso de lengua española, pág. 230).

(66) «Mario, mírame, anda, aunque sólo sea un momentín, por favor, no me vayas a confundir con mi hermana, me aterro sólo de pensarlo, te lo prometo, ya ves Julia, una cualquiera, no me digas, con un italiano, que no tiene perdón, en plena guerra, tú me dirás, como quien dice en frío, que al fin y al cabo, Galli, un desconocido, buena diferencia con Paco que perdería la cabeza y todo lo que quieras, pero, en resumidas cuentas, un caballero (...)» (Miguel Delibes, Cinco horas con Mario, pág. 281).

Las diferencias entre estos elementos habrá que buscarlas, pues, en el nivel de lengua funcional en que aparezcan.

\subsection{Total}

Comencemos con una breve referencia a la tradición lexicográfica española, aunque los datos que nos va a aportar no son en exceso valiosos. Tres valores posibles son los que la tradición atribuye a total: «resumen», «conclusión»y «consecuencia».

El DUE (1966-1967) considera este marcador como una 'expresión consecutiva que significa «después de todo lo dicho, ocurrido», etc.: En total, no sabemos a qué atenernos' (s.v. total) ${ }^{46}$.

El diccionario de la Academia (1992) dice a propósito de esta forma: 'En suma, en resumen, en conclusión' (s.v. total). Como veremos, esta forma no es de ningún modo equivalente (o sinónima) de ninguna de las tres que presenta la Academia.

No podemos afirmar que sea fácil presentar orientaciones más o menos claras que ayuden a delimitar los distintos empleos de este marcador. De cualquier forma, vamos a intentar sistematizar los usos que se han localizado tras el examen detenido del corpus.

46 Parece que según esta definición de $\mathrm{M}^{\mathrm{a}}$ Moliner, y teniendo en cuenta las formuladas para en resumen y en suma, estos dos últimos marcadores podrán ser conmutados por total siempre que tengan un valor consecutivo. Lo que sí ha desaparecido es el sentido de «condensar», de «abreviar» que tenía en resumen. 
En primer lugar, centraremos nuestra atención en el establecimiento de un valor más o menos general para esta forma. Dado que el contenido semántico de este término no ha desaparecido (al menos totalmente), podemos decir que con su utilización, lo que se propone el hablante es presentar un determinado resultado, relacionado, claro está, con lo que se dijo en fases precedentes. Podemos hablar de «total» en sentido matemático. El testimonio que se expone a continuación es válido para dar una idea aproximada de lo que queremos decir:

(67) «-Y es que somos tontas. Porque yo sé de una artista muy famosa, que por cierto ya no es ninguna niña, que ha hecho un lote y le ha vendido a una agencia la exclusiva del divorcio, del posterior romance, del subsiguiente matrimonio civil, del posible embarazo y futuro alumbramiento, del bautizo y, naturalmente, del nuevo divorcio.

- Vaya talento!

-Total, veinticinco millones de pesetas» (Fernando Vizcaíno Casas, Entremeses variados ${ }^{47}$, pág. 41 ).

Dos rasgos principales son los que hay que señalar a la hora de establecer el valor general de este marcador. Por un lado, está la idea de concluir, de poner punto final a lo anterior; y por otro, está la idea de mostrar el «resultado» al que intenta llegar el hablante, lo que él considera el núcleo de su enunciación. Su utilización en las enumeraciones ${ }^{48}$ es muy frecuente. Llegado un momento, el hablante considera que no es necesario proseguir con la enumeración y, para poner fin a la misma, echa mano de total $^{49}$ :

(68) «-Bueno Fina. Hace tres años que tú y yo empezamos este negocio. Tú y yo solos, $i$ te acuerdas? Has trabajado mucho..., me has ayudado como una

47 En adelante, $E V$.

48 Wemer Beinhauer 1978 atribuye a esta forma y a en fin un valor de recapitulación: 'la mayoría de las enumeraciones se cierran con una formulita que resume la impresión total. Para ello se emplean preferentemente cientas aposiciones introducidas, por lo común, con un en fin o total de recapitulación' (pág. 348).

49 A propósito de los rasgos entonativos de esta forma diremos que en lengua oral el final de la enumeración suele terminar en cadencia (con un volumen de la enunciación relativamente más bajo), y a continuación se pasa a pronunciar la forma total con semicadencia (con un volumen de enunciación más alto). Es importante tener en cuenta la entonación de este elemento a la hora de delimitar sus valores, ya que pronunciado con semianticadencia y con pausa menor (o incluso sin ella), pasa a funcionar como una «duda retórica» (afirma más que la no retórica). Así, la entonación se convierte en un rasgo pertinente en casos como el que sigue:

Totall[L] no sé para qué vino / Totall[T] no sé para qué vino.

En el segundo caso el hablante no entiende el comportamiento de otra persona, y parece compartir con el destinatario —o los destinatarios — un cierto conocimiento del mundo (el hecho de que esta actitud no sea muy lógica) que apoyará su razonamiento. 
bura... ¡ Che, ya me entiendes! Qué yo no sé hacer discursos. Toial, que quiero que tengas un recuerdo mío en este día tan histórico...» $(E V$, pág. 30).

Una vez formulado este valor general, pasamos ahora a los empleos discursivos más específicos:

A) Total como introductor de una recapitulación: en este caso el enunciado que introduce total presenta o bien una síntesis de lo mencionado anteriormente, o bien una conclusión (consecuencia). Tras la emisión de dicho enunciado, no hay intención de continuar con el tema que se venía tratando:

(69) «H: Y, bueno hombre, en plan estudios yo lo recuerdo muchísimo mejor que Santiago, con una diferencia... fundamental, pero... después era aburridísimo y (...). Claro, es que toda la semana metida en un Colegio Mayor sin poder salir, el fin de semana nadie salía, si salías tú sola pues... tampoco cra divertido; no conocías demasiado a gente de otros Colegios Mayores porque [ruido: alguien atraviesa el salón]... eran como guetos muy cerrados... Totai que... que más que un problema de ... de aburrirse que de... no estar contenta $)^{50}\left(\mathrm{CLO} \mathrm{O}^{5 \mathrm{M}} \mathrm{M}, 41-59\right.$, a).

B) Total como estrategia comunicativa para retomar el discurso: el hablante, después de «entretenerse» en cuestiones que considera «marginales» (podríamos hablar también de cuestiones «preliminares») con respecto al hilo discursivo que está siguiendo, vuelve a lo que considera el relato central de su exposición con un total. A diferencia del caso anterior, aquí hay una intención de continuar cor el tema del enunciado que esta forma introdujo. Este empleo se ha localizado en iengua oral y en lengua escrita de carácter coloquial. Veamos testimonios de ambos casos:

(70) «H: (...)Y entonces, «Bah, me pido la de carreras». «Mira, \#nombre\#, ¿no sería mejor una $\mathrm{BH}$, que es más pacífica, porque además ú en bicicleta, no recuerdo haberte visto en bicicleta nunca, y una de carreras es muy seria y tàl». "Quiero la de carreras, porque... luego la otra me va a quedar pequeñá, y ađemás pesan mucho», bueno, argumenté todo lo que me habían dicho mis amigos, ¿no?

\section{E: Sí}

H: Total que me compran la de carreras, y me lievan, en el coche, a la bicicleta y a mí hasta Oleiros, y me sueltan allí con los amiguitos (...) $)(C L O, \mathrm{H}$, $25-40$, a).

so En este caso la entrevistada, después de hacer referencia ai aburrimiento que «soportaba», pasa a exponer las razones que le produjeron el mismo. Podemos decir, pues, que la recapitulación del conjunto va expresada en dos ocasiones, una al principio y otra al final de la cnumeración.

s1 Corpus de lengua oral. 
(71) «-Te comprendo muy bien. O sea que iban seis. ¿Gente joven?

-Tres parejas, eso es. ¿Dónde he puesto los cigarrillos? Ah, gracias. Sí, jóvenes. De veinte a treinta años. Una de las dos chicas era más pequeña, tenơría unos diecinueve. Se pusieron a bailar. Estaban ya bastante bebidos. Margot sobre todo. Yo noté que quería hablar conmigo y nos hacíamos señas. Por otra parte, no me podía quitar de encima a aquel tipo. Otras veces me daba la impresión de que Margot se había olvidado de mí. Se lo estaba pasando en grande, haciendo el loco, besándose con un muchacho. Estaban de juerga, vamos. Total que, por fin, fuimos las dos al tocador y allí nos saludamos. Me contó que los había conocido en Madrid y que estaban haciendo un viaje por toda la costa» (Juan García Hortelano, Tormenta de verano, pág. 287).

En este sentido, es frecuente que intercaladas entre el marcador total y la secuencia que le sigue, se sitúen como elemento parentético expresiones del tipo «como tc iba diciendo», «como antes te dije», que después de una rupura temática más o menos larga, que puede implicar total desconex ión e introducción de un nuevo tema, facilitan al hablante la vuelta al tema inicial. En cl cjemplo siguiente, después de una interrupción por parte de otro hablante, se intenta volver al relato anterior:

(72) «H: Fuimos a comprar el televisor, llegamos a la tienda, vino el vendedor y nos enseñó varios...

E: ¿A qué tienda fuistcis?

H: A. San Luis. Total que, como te iba diciendo, cuando al fin ya lo habíanos clegido ... « (CLO, H, 25-40, m-a).

Finalizando ya, y tras hablar de estos dos usos discursivos, podemos esbozar una diferencia entre cllos. Si bien en el primer empleo de total el enunciado que introduce el marcador suele ser de menor extensión, en este segundo case no pone límites con respecto a la extensión de lo que le sigue.

\subsection{En conclusión / conclusión}

En primer lugar, como venimos haciendo hasta ahora, vamos a dirigir nuestra atención a la tradición lexicográfica española.

La Academia en su Diccionario (1992) propone los siguientes significados para en conclusión: 'En suma, por último, finalmente's2. Según el DUE (19661967) la forma en conclusión es una 'expresión con la que se pasa a decir una consecuencia a que se ha llegado, generalmente con decepción o disgusto: $E n$

57. Como tonciremos ocasión de comprobar más adelante, son pocos los empleos discursivos de finalmente y por ditimo yae sonden equiparar a los de en conclusión. 
conclusión, que no has hecho el trabajo's3. De cualquier forma, me parece excesivo hacer generalizaciones a este respecto. El corpus examinado, así como la propia competencia idiomática como oyente, no me permiten afirmar que sea frecuente la aparición de estos valores pragmáticos cuando se utiliza en conclusión.

Una vez más, podemos hablar de tres valores: «resumen», «cierre» y «consecuencia».

En realidad, creo necesario señalar que, aunque en teoría la distinción entre «conclusión» y «resumen» parece bastante clara - ambos presentan contenidos semánticos distintos-, en la práctica, «conclusión» y «resumen» son dos conceptos que están bastante próximos, no sólo por su extensión —que suele ser breve-, sino también por la posición que ocupan. De hecho, disponemos de testimonios que dan fe de esta proximidad. Veamos dos casos en los que el marcador conclusión aparece junto a en resumen y a en suma $a^{54}$ :

(73) «Conclusión: La octava, en resumen, es un excelente ejemplo del estilo de Góngora. Sin poseer dificultades insalvables - aquellas dificultades que valieron para don Luis el título de «Príncipe de las tinieblas»- sus rasgos culteranos son, sin embargo, densos: hipérbaton frecuente, metáforas osadas, adjetivación abundante... $\mathrm{Y}$ todo al servicio de una finalidad descriptiva y ponderativa plenamente lograda» (CCTL, pág. 125).

(74) «Conclusión: En suma, El árbol de la ciencia es tan barojiano por la índole de su contenido y enfoque como por sus aspectos formales. Acaso se trate, como afirma E. de Nora, de la más representativa de las novelas barojianas» (LE, pág. 98).

En ambos casos la «conclusión» que se introduce es un «resumen» de lo que se expuso en fases precedentes.

Podemos postular que el valor general de esta forma es el de presentar un enunciado que reformula lo mencionado con anterioridad y a la vez pone fin al discurso o a una parte de él. En cuanto a sus empleos discursivos vamos a realizar una distinción muy parecida a la que establecimos a propósito de las formas en suma, en resumen y similares. Distinguiremos dos tipos de conclusión:

s3 Del término conclusión M Moliner 1966-1967 presenta las siguientes acepciones: 'Fin, terminación, término. Acción de concluir o concluirse. 2. Consecuencia. Conocimiento o idea que se llega como final de un razonamiento. 3.Decisión o acuerdo tomado después de tratar de una cosa o pensar sobre ella: Después de hablar tres horas no hemos llegado a ninguna conclusión'(s.v. conclusión). Vemos cómo conclusión está asociada a la idea de finalizar algo, a la idea de «cierre». Además, vuelve a aparecer el término «consecuencia». En esta definición no se incorporan las notas que estaban presentes en el caso de en conclusión («decepción» o «disgusto»). Esta postura no es muy acertada ya que en la mayoría de los ejemplos (salvando las restricciones de la posición de conclusión) son conmutables.

\$4 Los dos están situados al final de un apartado de una lección. 
A) Conclusión parafrástica ${ }^{55}$ : formarán parte de este primer grupo, aquellos casos en los que el segmento que se presenta a modo de conclusión es el resultado de una síntesis de lo que se dijo $^{56}$ :

(75) «En conclusión, la trayectoria de Buero Vallejo resume, como ninguna otra, los pasos que ha seguido el teatro español más digno, y es ejemplo de rigor y fidelidad a las exigencias de su creación. Ya resultó excepcional que, con su naturaleza inquietante e inconformista, lograra abrirse paso en los años de la posguerra (...)» (LE, pág. 460).

B) Conclusión no parafrástica: aquí tendríamos que incluir aquellos otros casos en los que figura a modo de conclusión una deducción que se desprende de lo dicho anteriormente. Se tratará, pues, de una serie de consideraciones de un balance- que se extraen después del análisis e interpretación de los datos. En este sentido se aproxima mucho al valor consecutivo ${ }^{57}$. Este tipo de conclusión es muy frecuente en la prosa periodística. Vamos a ver dos testimonios, uno perteneciente a esta última, y otro perteneciente a la prosa didáctica:

(76) «Conclusión: Fraga carece de oposición política relevante, pero ve su tranquilidad alterada por una oposición social que tuvo su clímax el pasado día 2 en la plaza del Obradoiro, y se ramificó en protestas de enseñantes, sanitarios, trabajadores de empresas en crisis, músicos de orquestas y vecinos en pie de guerra localista como los de Fonsagrada. También en esto se parece a Felipe González, poco inquietado por los adversarios políticos y acosado en el frente sindical» (C. Luis Rodríguez, $L V G, 29.12 .91$, pág. 10).

(77) «En conclusión, estamos ante otra de las figuras excepcionales de la poesía escrita en castellano durante este siglo. Aunque en una obra tan abundante sean inevitables las caídas, son centenares de páginas que le otorgan un puesto privilegiado. $Y$ sus múltiples facetas han convertido a Neruda en un maestro para poetas de muy diverso signo» ( $L E$, pág. 533).

Como se habrá advertido a lo largo de este apartado, se ha tratado indistintamente a en conclusión y a conclusión. Esto se debe a que sus usos son los mismos. Podemos hablar de una diferenciación basada, además de en la movilidad oracional, en el tipo de lengua funcional en que aparecen. Así, en conclusión parece mostrar un carácter más coloquial.

ss Los términos reformulación parafrástica y reformulación no parafrástica -aunque no con un sentido equivalente al nuestro- son utilizados en algunos estudios referidos a la lengua francesa para designar dos tipos distintos de reformulación (Corinne Rossari 1990:348).

56 Compárese con la recapitulación condensadora.

57 Véase la recapitulación ¿valuativa. 


\subsection{En fin y finalmente}

La decisión de estudiar estos dos elementos de manera conjunta se debe a que si atendemos a su forma, vemos que pertenecen a la misma familia léxica. En ambos está presente el segmento fin. Además, y siguiendo la tónica general, parte de la tradición lexicográfica española trata estos términos como sinónimos. Así, el DRAE (1992) da dos acepciones de en fin: '1. Finalmente, últimamente. 2. En suma, en resumidas cuentas y en pocas palabras' (DRAE, s.v. fin). Con respecto a finalmente dice: 'últimamente, en conclusión' (DRAE, s.v.finalmente). Teniendo en cuenta que María Moliner 1966-1967 define en fin como una expresión "con que se pasa a exponer la conclusión o resumen de lo que se viene diciendo o hablando" (DUE, s.v. fin), da la impresión de que estos elementos pueden tener valores idénticos. Podemos hablar de tres valores comunes: «resumen», «conclusión»y «cierre»s

Lo que se intentará mostrar en este apartado es que no se puede hablar de equivalencia entre estos dos marcadores. Al no ser equivalentes funcionalmente, requicren un tratamiento separado.

\subsection{En fin}

Si algo define a este marcador es su multifuncionalidad, que hace especialmente difícil deslindar el valor general de lengua de los diferentes empleos ocasionales. En este caso, si bien a veces hay intención de abreviar, también se observa en no pocas ocasiones un deseo de finalizar, de no extenderse más, de concluir.

De cualquier forma, en líneas generales podemos hablar de un valor que subyace a todos los empleos de este elemento. En fin da al enunciado que introduce la función de «poner fin» a lo que precede ${ }^{59}$ :

(78) «... pero a nuestro hombre le fastidiaba el afán de mando de su esposa, comenzaron las discusiones, en los momentos de mayor crispación, ella echaba por delante su dinero, qué sería de ti sin mis pesos, ¿dime?, además el clima le senaba fatal, en fin, al medio año puso tierra de por medio...» (EV, pág. 204).

Una vez fijado el valor general podemos acercarnos ahora a los usos discursivos más específicos.

Jô Según J.J. Franckel 1987, también en francés la situación es similar: 'Finalement, en fin, à la fin: ces termes souvent présentés comro plus ou moins synonymes ne sont pourtant que rarement substituables les uns aux autres et impliquent des conditions d'emplois très différentes. Toutefois, la mise en jeu commune du marqueur fin leur confère une évidente parenté" (pág. 43).

59. Al marcador enfin del francés, con empleos próximos pero no equivalentes a los de la forma española en fin, A. Cadiot et alii 1985 le dan el valor general siguiente: 'En énonçant enfin, le locuteur signifie qu'une entité linguistique $X$ accompagnée par enfin fait qu' il n'y a plus lieu de donner à un discours $Z$ antêrieur à $X$ une suite $Y$ envisageable avant l'énonciation de X' (pág. 199). 
A) En fin en las enumeraciones ${ }^{60}:$ su empleo en una enumeración indica el cierre de la misma. Puede introducir o bien el último elemento de dicha enumeración, o bien un elemento que incluya a los demás $s^{6 i}$.

a) Como introductor del último elemento de una enumeración: éste inciica que la lista está completa:

(79) «Citemos, en fin, las novelas de esta última época, que son — según el autor- «esperpentos acrecidos y trabajados con elementos que no podrían darse en la forma dramática» « ( $L E$, pág. 194).

b) Como introductor de un elemento que incluye a los demás: al igual que en el caso anterior dispensa de continuar la enumeración. Este hecho responcie a que la intención comunicativa de dar una caracterización general está satisfecha. En este caso a la idea de «poner fin» habría que añadirle la de «abreviar», podríamos hablar de «fin» + «resumen»:

(80) «...Sentí que se me paraba el pelo, quería gritar, en fin, eso que se siente, a lo mejor usted ha tenido miedo alguna vez...» $(R$, pág. 52).

(81) «Visi es un encanto de chica, ya la verás. Es una chica moderna, con muy buen aire, inteligente, guapa, en fin, todo. Yo creo que la quicro mucho» (Camilo José Cela, La colmena ${ }^{62}$, pág. 161).

En lengua oral normalmente el final de la enumeración se pronuncia con suspensión (señal de que podría continuar) y el marcador en fin con semicadercia:

(82) «E1: Volviendo al tema de las cárceles, ¿hay malos tratos en las cárceles?

H: Hay de todo, de todo; tienen las celdas de castigo que se llaman, que son... recintos sin luz, y le dan media ración de comida; no tienes mantas ni sábanas, tienes que dormir desnudo, como se dice, con la ropa puesta y, y en la oscuridad allí durante $X$ tiempo, según el delito o la falta que hagas. Ahora, otra cosa no, allí la... es decir, pegar a los presos, esas cosas, únicamente que hagan una revuelta, no, si se ponen en plan bravo pues claro, pero lo demás no, no

to W. Beinhauer 1978 incluye a este elemento dentro de las «fómulas de enumeración»: 'La afición del hablante español por la enumeración llega hasta el punto de que para los casos en que el detallar las distintas cosas o circunstancias supone alguna dificultad, la lengua cologuial tiene a mano determinadas fómulas comparables a las abstracciones numéricas $(a+b+c)$ del álgebra. (...) El conjunto aparece recapitulado mediante un concluyente en fin, la mar de cosas, o algo similar. Con este resultado final se contenta una expresión más abstracta' (pág. 343).

61 Hablo de «elemento» simplemente por comodidad, pero debo precisar que dicho cicmento puede ser de distinta exıensión, puede tratarse de una palabra, de una oración, ctc.

62. En adclante, $L C$. 
hay... otro problema. Y después claro, eso, que la rigidez que tienen que comer a su hora, levantarse a las seis de la mañana... en fin, etc., etc.» $(C L O, \mathrm{H}, 60-, \mathrm{b})$.

A través de todos estos ejemplos se observa que el individuo que hace la enumeración, la encuentra fastidiosa, imposible o no interesante. De ahí que utilice una etiqueta más genérica que considera suficiente para dar a conocer el conjunto. En estos casos la noción de conocimiento compartido juega un papel importante, ya que esa etiqueta más genérica de la que hablamos es un simple «eso», «todo» 0 «etc, etc». El hablante piensa que, después de las características esbozadas, lo que vendría a continuación puede ser fácilmente inferido por el destinatario ${ }^{63}$.

B) En fin conclusivo o de resumen: considero preferible tratarlos de forma conjunta porque individualmente son muy difíciles de delimitar. Su sentido está muy próximo al de en conclusión y al de en resumen (o en resumidas cuentas). Aparece normalmente en posición final de un texto, y lo que se introduce es una deducción de lo dicho anteriormente o una recapitulación. Al igual que hicimos en el caso anterior, hablaremos de «fin»+ «conclusión» y «fin»+ «recapitulación»:

(83) «La «Suite» de Munteanu es bella de efectos orquestales y vocales, aunque de estrofas un tanto repetitivas. Me gustaria haberla oído bajo otra batuta. En fin, un concierto gris» (Ramiro Cartelle, $L V G, 15.12 .91$, pág. 40).

63 Se podría postular la presencia (sobre todo en lengua oral) de testimonios en los que en fin se situase tras una enumeración completa. Este es un empleo que se ha constatado en la lengua francesa. Pero - y permítaseme la osadía, ya que sólo me guía mi intuición como hablante- en este sentido creo que podríamos adaptar al castellano dicho empleo. Tomemos, pues, un ejemplo similar al utilizado por Anne Cadiot et alii 1985 para el francés:

A: ¿Con quién estabas ayer en el restaurante?

B: Estaba con María, Juan y Pedro, en fin, con mi hermana y mis dos hijos.

Según estos autores este ejemplo es «embarrassant», ya que «con mi hermana y con mis dos hijos» no parece dispensar de continuar una enumeración inacabada, puesto que esta enumeración, en la situación imaginada, ya está completa (pág. 206).

Desde mi punto de vista, creo sería válido considerar que en este caso, y en casos paralelos, el segmento introducido por en fin tiene un valor explicativo. De este modo, encontramos una cierta conexión con «la reformulación» con carácter de «precisión» de la que habla Manuel Casado Velarde 1991 al estudiar la «explicación» y sus tipos: 'Implica equivalencia de la designación y/o sentido (...) La diferencia existente entre el primer segmento y el segundo (o segmento reformulado) radica en el contenido idiomático (significado). No se establece jerarquía entre los segmentos, que constituyen dos formulaciones igualmente factibles. Esto posibilita la inversión del orden de los segmentos' (págs. 108-109). De cualquier forma, en el caso del marcador que nos ocupa, esta última afirmación relativa a la posibilidad de inversión del orden de los segmentos, habrá que tomarla con precaución. Pensemos que quizá sea más probable la formulación del ejemplo que dimos anteriormente que ésta:

A: ¿Con quién estabas ayer en el restaurante?

B: Estaba con mi hermana y mis dos hijos, en fin, con María, Juan y Pedro. 
C) En fin de resignación: este tipo responde a una intención comunicativa diferente a la de los ejemplos anteriores. A este en fin le siguen normalmente expresiones que indican resignación por parte del hablante ${ }^{64}$ :

(84) «-Por supuesto. Increíble, ineluctable, todo eso. Nada de necrologías, viejo. En esta pieza ha bastado que me fuera un día para que pasaran las cosas más extremas. En fin, lo uno servirá de consuelo para lo otro» ( $R$, pág. 145).

(85) «-Lo está siempre, yo creo que nació ya de mala uva. ¡Mi cuñada es una bestia parda! iSi no fuera por las niñas, ya la había puesto yo las peras a cuarto hace una temporada! Pero, en fin, ipaciencia y barajar! Estas tías gordas y medio bebidas suelen durar mucho» ( $L C$, pág. 120).

Como se habrá podido observar, los testimonios anteriores pertenecen todos a lengua escrita, por ello se hace imprescindible la presencia de un léxico relacionado con la idea de resignación en el contexto inmediato («consuelo», "paciencia», etc). Sin embargo, en lengua oral, el contexto y los matices entonativos - pronunciado con suspensión o cadencia y, por lo general, con un tempo relativamente más lento- hacen que este empleo se manifieste con una mayor claridad:

(86) «E2: Pero, ¿y la degradación del medio ambiente?, ¿por qué lo estamos destruyendo?

$\mathrm{H}$ : Ah, ja, ja, ja, eso sí; eso sí, eso, no guardamos respeto a nada. Ni las fábricas... eso nada, eso no hay que ... y la caza, porque partiendo ya de eso, pues no debían de cazar a los animales; los animales como las liebres y tal y que, con quién se meten esos animales, con nadie, y venga «pum, pum, pum...».En fin, eso, son cosas, ya las ballenas, por ejemplo. Buah, hay muchos animales. Ahora quieren matar vacas porque dicen que hay muchas, que hay demasiadas; venía en el periódico de hoy, también una cosa... que me parece una salvajada, lo habrá que, que regular, el nacimiento de esas, pero de momento matarlas... sería una, una brutalidad» $(C L O, \mathrm{H}, 60-, \mathrm{b})^{65}$.

Con cierta frecuencia este empleo de en fin va seguido de un silencio que sustituye al discurso que se hubiese podido producir. El hablante juzga que para

${ }_{64}$ Un ejemplo de este tipo lo presenta Ana $M^{3}$ Vigara Tauste 1980 , pero no hace ninguna referencia a un empleo discursivo concreto. Se limita simplemente a decir que actúa 'como introductor de enunciados sin valor conclusivo' (pág. 76): (idem).

-Pues... No sé... Se me fue el santo al cielo... No sé lo que iba a decirle... En fin, iya me acordaré!

6s Existe la posibilidad de combinar empleos discursivos. Así, los matices de resignación pueden aparecer en cualquiera de los ejemplos pertenecientes a los grupos que se establecen dentro de este apartado. 
ser entendido no necesita completar su enunciado:

(87) «Don Roque tiene sus reglas particulares de cartomancia.

La sota de bastos salió en tercer lugar. 134)

-iPobre Lola, lo que te espera! ¡Te compadezco, chica! En fin...» ( $L C$, pág.

(88) «'Esta pieza está tan desordenada', pensó, besando a Talita. Apenas dejara de llorar le pediría que lo ayudara a acomodar el cuarto. Empezó a acar ciarla, a decirle cosas.

-Enfin, en fin —dijo Oliveira» ( $R$, pág. 250).

D) En fin de connivencia ${ }^{66}$ : va acompañado de expresiones del tipo «ya me comprendes», «no sigo», «ya sabes a lo que me refiero», etc. Debido al carácter eufemístico de lo mencionado con anterioridad, se indica que no se va a continuar con el tema:

(89) « ... Don Marciano confía en que lo comprenda; le envía sus más fervinentes excusas; mañana le llamará por teléfono a la hora de costumbre. Ha tenido que abandonar el local por la puerta de servicio.

- Humillante para un subsecretario.

- Sin embargo, en sus circunstancias... Se trata de un hombre público, debe cuidar su look, ya sabe, la imagen. En fin: no creo preciso insistir sobre el tema» (EV, pág. 151).

Il destinatario puede ser consciente inmediatamente de que se trata de un asur to «espinoso», «comprometedor». Si por el contrario, no lo hiciese, ei empleo de este marcador provoca que el interlocutor descubra dicho carácter eufemistico.

E) En fin de rectificación: el hablante, después de hacer una determinada afirmación, utiliza en fin para introducir una precisión, referida a algo dicho previamente ${ }^{67}$ :

90) «-No volverá - dijo la Maga-. En fin, tendrá que venir para buscar sus cosas, pero es lo mismo. Se acabó, kaputt» $(R$, pág. 126).

Uste uso lo recogen A. Cadiot el alii 1985 para la forma francesa enfin. Utilize este término como traducción del empleado por ellos: «connivence» (pág. 227).

6) Entre los emplcos que M. Casado Velarde 1991 otorga a los marcadores es decir, esto es, o sea y a saber, está al de «reformulación» con carácter de «rectificación». Este uso cstá muy próximo al que ahora nes ocupa: "No implica equivalencia; por el contrario, lo reformulado difiere, en la designación yio en el sentido, de lo dicho en el primer segmento, que queda modificado ocorregide' (pág. 109). 
(91) «-Pero usted trabaja, se ve - lo acusó la clocharde.

-Oh, no. En fin, le llevaba los libros a un viejo, pero hace rato que rio ros vemos» ( $R$, págs. 199-200).

Todo apunta a que los deseos del emisor se dirigen a evitar un malentendido. Sobre todo en este segundo ejemplo, creo que el propósito de la introducción de en fin es el de invalidar cualquier recriminación o protesta por parte del oycnite ${ }^{68}$.

F) En fin introductor de un cambio de tema: indica que se deja de lado un tema y se continúa con otro nuevo, o bien, que se retoma uno mencionado anteriormenic:

(92) «-Qué ticmpos, ¿verdad, Martín?

- Sí, Filo, iqué ticmpos! Pero ya se arreglarán las cosas, tarde o temprano.

- ¿Tú crees?

- No lo dudes. Es algo fatal, algo incontenible, algo que tiene la fuerza do las mareas.

Martín va hacia la puerta y cambia de voz.

—En fin ... ¿Y Petrita?» (LC, pág. 91) ${ }^{69}$.

(93) «El último cliente, don Romualdo Cañizares Pardezuelá, acababa ds marcharse (...) Naturalmente, Romualdo, que es solterón, no resulta cliente apetecible dada la cortedad de sus comidas (...) Pcro justamente el 15 de mayo, festividad de San Ísidiro Labrador, patrono de Madrid, puso de manifiesto unas virtudes ciudadanas que le conquistaron el afecto de Sento. Almorzaban junto a una mesa tres individuos (...) En fin, como veníamos diciendo, aquella otra tarde ya se había marchado el valeroso ex sargento (...)» (EV, págs. 64-66).

G) En fin soporte conversacional ${ }^{70}$ : dentro de este tipo se incluirán los usos de este marcador como expletivo. He preferido evitar esta última denominación

68 Este empleo respondería a esa propiedad conversacional en verti de laqueile ta plajart des interventionss se présénteni comme répliquani à un discours réel ou possible de l'aure' (A. Cádic: et alii 1985:229).

6 En este caso es significativa la precisión del autor de la obra al indicar que ei personaje para pronunciar esto último «cambia de voz». Además, se está dirigiendo hacia la pucrta con el propósito de marcharse, de ahí su intención de no proseguir con el asunto del que estaban hablando.

7w El término de «soporte conversacional» lo utiliza Ana Ma Vigara Tauste 1980 y 1992. Esia aviora en Aspectos (1980) hace algunas afimaciones que no podemos compartir: 'Estos recursos expresivos formarían parte de las generalmente reconocidas «fómulas de relleno». Lo que caracteriza a estos «soportes» coloquiales es su carácter pasivo, respecto del hablante y su interlocutor ( ....) (pág. 66). Sin embargo, en su obra posterior, Morfosintaxis del español coloquial (1992), hace unia serie de matizaciones sobre los enlaces coloquiales (uno de los tipos de «soporte conversacionais) que consideramos acertadas: "Si decimos «superfluos» o «prescindibles» debemos matizar siemion «desde el punto de vista lógico» o «desde el punto de vista gramatical», que no desde la perspecivá de la comunicación coloquial, en la que constituyen, como hemos visto, un «relleno» necesario para su progresión natural y fluida' (pág. 249). 
porque normalmente por ella se entiende que son términos «vacíos de significado» (L. Cortés Rodríguez 1991:29). En tal caso podríamos decir que carece de contenido semántico, pero no pragmático. El hablante los pone al servicio de su discurso, como un apoyo de la elocución. En la mayor parte de los testimonios, responden a titubeos del hablante y a un intento de ganar tiempo para pensar lo que se va a exponer a continuación, actuando como una fórmula retardataria:

(94) «-... Yo creo que aquí no hemos venido solamente porque el Dire nos trae. Era fácil quedarse en el circo con Suárez Meilán, conocemos el trabajo y nos aprecian. Pero no, había que entrar aquí. Los tres. El primer culpable soy yo, porque no quería que Talita creyera... en fin, que te dejaba de lado en este asunto para librarme de vos. Cuestión de amor propio te das cuenta» $(R \text {, págs. 289-290 })^{71}$.

Como se habrá podido comprobar, los ejemplos que ilustraron los diversos empleos discursivos de en fin proceden del corpus de lengua oral y del corpus de lengua escrita. Este marcador es de uso frecuente en ambos registros. Sin embargo, debemos advertir que determinados valores, como el mencionado en último lugar, son típicos de la lengua oral. Obviamente, este hecho se deriva de las características definitorias de estas dos modalidades del lenguaje.

\subsubsection{Finalmente}

Una vez presentados los usos discursivos de en fin, no resulta difícil comprobar que la sustitución de en fin por finalmente no funciona en la mayoría de los ejemplos ${ }^{72}$. Vemos, pues, que la consideración de estos dos términos como sinónimos es incorrecta.

En primer lugar, vamos a establecer el valor general de esta forma. La utilización de finalmente tiene que ver con la presentación de un enunciado que se caracteriza por ser el último de una sucesión de sucesos, afirmaciones o puntos de vista. Siguiendo la diferenciación propuesta por Halliday y Hasan 1976 -relación externa $v s$. interna-, podemos decir que la dimensión temporal de esta forma le permite hacer referencia al orden temporal en que se han sucedido los hechos que se describen (externa), y referirse al último hito de una cadena argumentativa (interna, en este caso afecta al texto en cuanto tal). Veamos testimonios de ambos casos:

(95) «La gastronomía, que es una forma de nuestra cultura, estả tan en baja como la literatura, la filosofía o la honestidad, que es otra forma de la cultura.

71 Aquí el empleo del marcador como apoyo discursivo, tiene que ver con una situación en la que el hablante tiene dificultades para expresar lo que debe decir, porque el asunto es «delicado» y podría molestar a su interlocutor.

72 Compruébese en (80), (81), (84), (94), etc. 
Uno va a un restaurante en Madrid, Barcelona o en cualquier otra ciudad española que presuma de cosmopolita y lo recibe la publicidad engañosa de la carta (...). El ambiente - el marco- en que se desarrolla la colación es digno, casi suntuoso (...). El servicio es otra historia. Exteriormente, parecen eficientes, impecables. Sus modales no son aburridamente distantes o respetuosos, como antes, sino rústicos, cariñosos.

Finalmente, cuando vienen a tomar el pedido, se apoyan graciosamente en la mesa o en el hombro del comensal, con esa camaradería que es la esencia de la solidaridad y la democracia» (Oscar Peyrou, $L V G, 14.12 .91$, pág. 9).

(96) «Finalmente, aludiremos a la producción dramática de Ramón Gómez de la Serna (1888-1963), padre del vanguardismo español» (LE, pág. 182).

Una vez establecido el valor general, podemos pasar al tratamiento de los empleos discursivos de este elemento:

A) Finalmente en las enumeraciones: con él se introduce el enunciado que ocupa el último lugar:

(97) «(...) El sondeo también se interesaba por el número de días que, cada semana, los estudiantes veían la televisión, oían la radio o leían la prensa. En el caso de la televisión (...) La radio es, según el estudio, el medio más popular entre los universitarios (...) Finalmente, en el apartado de prensa, el 37\% de universitarios lee periódicos todos los días (...)» $(G U, 31.5 .93 \text {, pág. 14 })^{73}$.

Con cierta frecuencia entra en correlación con expresiones del tipo de en primer lugar... en segundo lugar...; por un lado... por otro...; etc. ${ }^{74}$ Sirva de muestra el siguiente testimonio:

(98) «El ánimo difamatorio de McLear alcanza su culminación cuando manipula dialécticamente las conclusiones del Encuentro: «En primer lugar, reconoce que estamos viviendo una época de evolución religiosa (evolución del mercado religioso) como consecuencia de los cambios políticos acaecidos en la Europa del Este. En segundo lugar, percatarse de la necesidad de una nueva evangelización (nuevas estrategias propagandísticas) para difundir el cristianismo (vender el producto) a nivel mundial. Finalmente, aprender a mantener una mejor coordinación entre todas las comunidades cristianas para mejor repartirse el pastel» (Horacio Carballal, EIG, 16.12.91, pág. 46).

73 Son frecuentes los casos como éste, en que se anticipa al principio los temas que se van a tratar.

74 Con respecto a esta cuestión dicen Halliday y Hasan 1976: 'The sense of temporal successivity in the enumeration of points in an argument is clearly shown by the strong tendency to anticipate a sequence of points by the use of the cataphoric conjunctive first, or related expressions such as in the first place' (pág. 264). 
E) Finalmente de resolución ${ }^{75}$ : se encuentra asociado a empleos que marcan un resultado final (o un punto de vista definitivo) precedido de dudas e incertidumbre:

(99) «María Inés va al Orfelinato donde se encuentra con Rosario y habla con la directora del centro sobre los planes que tiene respecto a la niña. Finaimente, Raúl y Clara Eugenia se casan. Este matrimonio no convence a Isabel (...) $\gg^{76}$ (Suplemento TV, 15-21 de mayo de 1993, no 290, pág. 6).

$\checkmark$ inculados a este tipo de empleo que indica duda o incertidumbre están ejemplos como ei que sigue:

(100) Finalmente, llovió.

Este uso también puede tener que ver con la presuposición de un contexto no favcrable a la posibilidad de un determinado hecho ${ }^{77}$.

(101) Finalmente, ese problema no resultó tan difícil de resolver ${ }^{78}$.

Este marcador posee, pues, una serie de usos discursivos que la forma en fin desconoce.

\subsection{Por último}

Abordamos ahora el estudio de un marcador que hay que poner en relación con ios dos anteriormente tratados; con ellos comparte la posibilidad de introducir

75 Este uso queda más o menos esbozado con las dos acepciones que $\mathbf{M}^{2}$ Moliner 1966-1967 presenta de este elemento: ' 1 . En último lugar o después de diversas vicisitudes: «Finalmente, nos invitaron a cenar». 2. Como decisión final: «Finalmente, que no me conviene’ (DUE, s.v. finalmente).

is Se presupone un contex to en que se ponía en duda la celebración de una boda. Un ejemplo may parecido a éste lo propone la gramática de la Academia (1931): 'FINALMENTE sc casaron'. Allí se dice que con adverbios de este tipo nos referimos 'a determinadas operaciones del espíritu humano'; y que esta frase se podría traducir «con toda fidelidad» - la cursiva es nuestra-por esta otra: 'pongo FIN a mi cuento diciendo que los amantes se casaron' (pág. 123). No creemos que esta tradueción pueda reflejar «fielmente» el contenido de dicha secuencia, ya que ésta presupone algo más.

7 En este sentido, coincide con uno de los empleos de la forma francesa finalement. Así lo expone M. Schelling 1983: "présente rétroactivement les constituants sur lesquels il enchaîne comme orientés pour des visées argumentatives $(r)$ contradictoires; la conclusion $(R)$ se présentant comme le résultat a' une évaluation du caractère contradictoire de celles-ci' (pág. 170). E. Roulet 1987 a propósito de este elemento hace la siguiente precisión: 'il peut donc, comme l'avait déjà noté Jayez (1983, 36), articuler aussi bien des élém?nts concordants que des éléments discordants' (pág. 129). Este rasgo es el que lo diferencia de otros «conectores reformulativos» que sólo pueden reformular elenientos del mismo signo (E. Roulet 1987:127).

7 Imaginemos un contexto en el que se pensaba que ese problema iba a ser difícil de resolver (c er: última instancia que había dudas sobre su resolución). Tanto en este caso como en los dos anteriores es posible la sustitución por al final (quizá esta última forma es más frecuente). 
un enunciado en último lugar. Por tanto, es una forma que desempeña la función textual de «cierre».

El diccionario de la Real Academia (1992) presenta estas acepciones del término: 'Después o detrás de todo, finalmente' (s.v. último). La equiparación con finalmente no tiene mucho sentido, puesto que en muchos contextos no son intercambiables sin que se produzca una variación en la interpretación de la secuencia.

A diferencia de en fin y finalmente, este marcador cuenta con un número muy limitado de empleos discursivos. Para el establecimiento de su valor general nos limitaremos a citar la definición propuesta por $\mathrm{M}^{\mathbf{a}}$ Moliner 19671967. Según esta autora, se trata de una 'frase muy frecuente con que se expresa algo con lo cual se piensa terminar la exposición' (s.v. último ${ }^{79}$. Veamos algunos ejemplos:

(102) «Y por último, Mingote reflexionaba respecto a que la mejor política posible sería aquella en la que coincidieran todos, y que sólo discreparan en el color de las corbatas» (Emilio Romero, $L V G, 20.12 .91$, pág. 12).

(103) «Por último, es obligado mencionar aquí a estas personas que trabajan desinteresadamente por llevar arriba un proyecto en el que verdaderamente creen, un proyecto - insisto- que sin la ayuda de hombres como Bobillo o mujeres como Maribel y un montón de ellos que no nombro sería imposible lograr para el pueblo caldense lo que ellos y solamente ellos han conseguido» (Jesús Antonio Goldar Güimil, ECG, 17.12.91, pág. 32).

Su empleo es frecuente en las enumeraciones para presentar el segmento que va en último lugar. Al igual que sucedía con finalmente, la utilización de esta forma implica que la enumeración que se cierra está completa ${ }^{80}$ :

(104) «Y unido a esto aparece la concesión de tres títulos nobiliarios. A Alfonso Escámez, como marqués de Águilas, que es su ciudad natal; a Juan Antonio Samaranch, por su larga carrera política y por una biografía interior de rico anecdotario y que llevará como título el de su apellido.

Y, por último, el Marquesado de los Jardines de Aranjuez a ese gran músico que es el maestro Joaquín Rodrigo» (Emilio Romero, $L V G, 29.12 .91$, pág. 15).

A menudo aparece con secuencias correlativas del tipo de en primer lugar... en segundo lugar...; de una parte... de otra parte...; por un lado... por otro

79 También aquí se puede hacer la distinción entre relación externa e interna, según haga referencia al orden temporal en que se han sucedido los hechos o haga referencia al proceso de comunicación en sí mismo.

so Recuérdese que el empleo de en fin en las enumeraciones no siempre indicaba que la lista estuviese completa. 
lado..., etc.:

(105) «(...) Pero los escasos datos que existen sobre el caso indican que los acontecimientos no se desarrollaron de esta manera, y que la detención es obra de una labor de investigación previa. Por un lado, en la comisaría de Ribeira (donde estaba destinado el inspector) existía constancia desde hace tiempo de las peligrosas amistades que frecuentaba el jefe de la protección civil coruñesa. Por otro, la policía estaba sobre la pista de su compañera sentimental. Por último, en el caso intervienen agentes especiales, una unidad similar a los famosos Intocables de Eliot Ness» (Leoncio González, LVG, 27.12.91, pág. 24).

Como hemos podido observar, ésta es una forma que se aproxima mucho a finalmente, pero de ninguna manera se puede hablar de equivalencia o de sinonimia entre estos dos marcadores.

\section{CONCLUSIONES}

- Las unidades que funcionan como marcadores con función textual de «resumen», «conclusión» y "cierre» no han sido objeto de estudio particularizado en lo que a la lengua española se refiere.

- Las formas que se estudiaron están todas lexicalizadas, aunque podemos hablar de una diferencia de grado, diferencia que se manifiesta, entre otras cosas, en su movilidad oracional. Así, generalmente cuanto mayor es el grado de lexicalización, más libertad tienen para poder ocupar cualquier posición en la secuencia. De cualquier forma, existen otros recursos válidos regulados idiomáticamente para expresar las funciones textuales mencionadas.

- Hemos visto que la presencia del marcador siempre es pertinente frente a su ausencia. Incluso en aquellos casos que más se aproximan a lo que se ha venido denominando «expletivos», su desaparición, si no influye en el contenido semántico de una secuencia, sí lo hace en el pragmático.

- En referencia a la relación sintáctica que instauran entre los segmentos que relacionan, cabe decir que no se puede equiparar a las que se establecen en el marco oracional. Hablaremos, pues, de «concatenación», una de las relaciones sintagmáticas que se producen en el nivel del texto.

- En lengua escrita estos elementos se sitúan entre pausas, constituyendo unidades fónicas independientes, pero en lengua oral no siempre se realizan las pausas.

- En cuanto a la colocación de estos elementos, hay que decir que se caracterizan por la «doble adherencia». Esta es la razón por la cual ninguno de ellos puede ocupar posición inicial absoluta, a menos que se pretenda conseguir un efecto especial. En relación con su posición en el enunciado, hay que 
establecer una distinción. En resumen, en suma, en resumidas cuentas, en conclusión, en fin y finalmente no presentan ningún tipo de restricciones con respecto a su colocación en el marco del enunciado. Por el contrario, resumen, conclusión, total y por último presentan restricciones en mayor o menor grado.

- Cuando el segmento que acompaña al marcador, a veces se puede suprimir sin que por ello se modifique sustancialmente el contenido de la secuencia. En cualquier caso, la proximidad de un verbo subordinante explícito en el enunciado hace que su presencia sea pertinente.

- En las obras lexicográficas estas formas aparecen a menudo presentadas como sinónimas. En realidad, la proximidad entre las funciones textuales de «resumen», «conclusión» y «cierre» dificulta la delimitación de los valores y usos discursivos de estos marcadores.

- Resulta poco menos que imposible ofrecer una nómina completa de todos los empleos discursivos de estas formas, ya que la polivalencia de las mismas obedece a factores pragmáticos. Por ello, se impone la necesidad de trascender lo puramente lingüístico-funcional para abordar el análisis de los usos de los marcadores.

- El valor general de en resumen, en suma (resumen y en resumidas cuentas) es la recapitulación sintética. Podemos hablar de dos empleos discursivos, recapitulación condensadora y recapitulación valorativa o evaluativa. Las diferencias entre estos elementos habrá que buscarlas en el nivel de lengua funcional en que se encuentran y en sus posibilidades distribucionales.

- Con el empleo de total lo que prima es el deseo de finalizar con el asunto del que se venía hablando y de presentar el resultado al que el hablante quiere llegar. Este elemento puede introducir una recapitulación de lo expuesto o puede funcionar como estrategia comunicativa para retomar el discurso.

- Reformulando lo que se ha dicho con anterioridad y poniendo fin a un discurso aparece en conclusión o conclusión. Se han establecido dos tipos de conclusión: parafrástica o no parafrástica. Las diferencias entre estos dos marcadores también habrá que buscarlas en la lengua funcional y en sus posibilidades distribucionales.

- En cuanto a las formas que desempeñan la función textual de «cierre», tenemos que citar a en fin y finalmente. Éstas con frecuencia se consideran sinónimas. Ambas tienen la misma base léxica «fin». Sin embargo, los empleos discursivos de en fin superan con creces a los de finalmente. Así, para en fin se han documentado siete usos (en las enumeraciones, conclusivo o de resumen, de resignación, de connivencia, de rectificación, introductor de un cambio de tema y soporte conversacional), frente a los dos que se han establecido para finalmente (en las enumeraciones y de resolución). Por tanto, no pueden funcionar siempre en los mismos contextos.

- En relación con las anteriores, pero con un número de empleos discursivos 
mucho menor, está por último. Tiene que ver con la idea de cerrar un tex to o una parte del mismo. Puede aparecer en las enumeraciones. En este sentido, al igual que finalmente, a menudo entra en correlación con otras expresiones, que indican algún tipo de orden o relación lógica.

\section{RERENCIAS BIBLIOGRÁFICAS:}

ACADEMIA ESPAÑOLA. 1931. Gramática de la lengua española. Madrid: Espasa-Calpe.

ACADEMIA ESPAÑOLA. 1992. Diccionario de la lengua española. $21^{\text {a }}$ edic. Madrid: Espasa-Calpe.

ÁLVAREZ MENÉNDEZ, ALFREDO I. 1990. Funciones y valores de pues en español. En Ma․ Ángeles Álvarez Martínez (ed.), Actas del congreso de la Sociedad Española de Lingüística. XX Aniversario, I. 307-317.

BEINHAUER, WERNER. 1978. El español coloquial. $3^{\text {a }}$ edic. corregida, aumentada y actualizada (original alemán de 1958). Madrid: Gredos.

BERNÁRDEZ, ENRIQUE. 1982. Introducción a la lingüística del texto. Madrid: Espasa-Calpe.

BRIZ, ANTONIO. 1993. Los conectores pragmáticos en español coloquial: su función metadiscursiva, comunicación presentada al XXIII Simposio de la Sociedad Española de Lingüística. Lérida.

BRIZ, ANTONIO (en prensa). Los conectores pragmáticos en español coloquial: su papel argumentativo. Contextos.

CADIOT, A., DUCROT, O., FRADIN, B. y NGUYEN, T.B. 1985. Enfin, marqueur metalinguistique. Journal of Pragmatics 9. 199-239.

CASADO VELARDE, MANUEL. 1991. Los operadores discursivos es decir, esto es, o sea y a saber en español actual: valores de lengua y funciones textuales. Lingüistica Española Actual XIII. 1. 87-116.

CORTÉS RODRÍGUEZ, LUIS. 1991. Sobre conectores, expletivos y muletillas en el español hablado. Cuadernos de Lingüística 10. Málaga: Ed. Librería Ágora.

COSERIU, EUGENIO. 1981. Textlinguistik: Eine Einführung. Tubinga: Gunter Narr.

COSERIU, EUGENIO. 1992. Competencia lingüística (Elementos de la teoría del hablar). Madrid: Gredos.

FRANCKEL, JEAN-JACQUES. 1987. Fin en perspective: finalement, enfin, $\grave{a}$ la fin. Cahiers de Linguistique Française 8. 43-67.

FUENTES RODRIGGUEZ, CATALINA. 1987. Enlaces extraoracionales, Sevilla: Alfar.

GARCÍA PELAYO, RAMÓN y TESTAS, JEAN. 1987. Larousse moderno 
(français espagnollespañol francés). Barcelona: Larousse.

GILI GAYA, SAMUEL. 1961. Curso superior de sintaxis española. $8^{\underline{a}}$ edic. corregida y aumentada. Barcelona: Vox

GILI GAYA, SAMUEL. 1991. Diccionario Manual de Sinónimos y Antónimos. $8^{\mathrm{a}}$ edic. revisada, actualizada y ampliada. Barcelona: Vox

GUTIÉRREZ ARAUS, Mª LUZ. 1978. Las estructuras sintácticas del español actual. Madrid: SGEL.

HALLIDAY, M.A.K. y RUQAIYA HASAN. 1976. Cohesion in English. Londres: Longman.

LÁZARO CARRETER, FERNANDO. 1984. Diccionario de términos filológicos. $3^{\underline{a}}$ edic. corregida. Madrid: Gredos.

MARTÍN ZORRAQUINO, Ma ANTONIA. 1988. Elementos de cohesión en el habla de Zaragoza. I Curso de Geografía lingüística de Aragón. Zaragoza: Institución «Fernando el Católico». 253-286.

MARTÍN ZORRAQUINO, Maㅗ ANTONIA. 1992. Partículas y modalidad. En Günter Holtus, Michael Metzeltin y Christian Schmitt (eds.), Lexikon der Romanistischen Linguistik. vol. VI, 1: Aragonesisch/Navarresisch, Spanisch, 110-124. Tubinga: Max Niemeyer.

MEDEROS MARTÍN, HUMBERTO. 1988. Procedimientos de cohesión en el español actual. Santa Cruz de Tenerife: Aula de Cultura de Tenerife.

MOLINER, MARÍA. 1966-1967. Diccionario de uso del español. Madrid: Gredos. ORTEGA OLIVARES, JOSÉ. 1986. Aproximación al mecanismo de la conversación: Apéndices «justificativos». Verba 13. 269-290.

QUIRK, R., GREENBAUM, S., LEECH, G. y SVARTVIK, J. 1985. A comprehensive grammar of the English language. London: Logman.

ROSSARI, CORINNE. 1990. Projet pour une typologie des opérations de reformulation. Cahiers de Linguistique Française 11. 345-359.

ROULET, EDDY. 1987. Completude interactive et connecteurs reformulatifs. Cahiers de Linguistique Française 8. 111-140.

SCHELLING, MARIANNE. 1983. Remarques sur le role de quelques connecteurs (donc, alors, finalement, au fond) dans les enchaînements en dialogue. Cahiers de Linguistique Française 5. 169-187.

STATI, SORIN. 1990. Le transphrastique. Paris: PUF.

VIGARA TAUSTE, ANA MARÍA. 1980. Aspectos del español hablado (Aportaciones al estudio del español coloquial). Madrid: SGEL.

VIGARA TAUSTE, ANA MARÍA. 1992. Morfosintaxis del español coloquial (esbozo estilístico). Madrid: Gredos.

VILARNOVO, ANTONIO. 1991. Teorías explicativas de la coherencia textual. Revista Española de Lingüística 21, 1. 125-144. 


\section{NÓMINA DE FUENTES}

BAROJA, PIO. 1985. El árbol de la ciencia. Madrid: Cátedra CELA, CAMILO JOSÉ. 1985. La colmena. Barcelona: Noguer.

Corpus de lengua hablada en La Coruña. Departamento de Lingüística General y Teoría de la Literatura. Facultad de Humanidades. Universidad de La Coruña.

CORTÁZAR, JULIO. 1985. Rayuela. Madrid: Planeta-Agostini.

DELIBES, MIGUEL. 1974. Cinco horas con Mario. Barcelona: Destino.

El Correo Gallego. Santiago. 5.12.91; 12.12.1991; 15.12.1991; 17.12.91; 25.12.1991.

El Ideal Gallego. La Coruña. 8.12.91, 16.12.91; 23.12.91.

Gaceta Universitaria. Madrid. 22.3.93, 31.5.93.

GARCÍA HORTELANO, JUAN. 1989. Tormenta de verano. Madrid: Clásicos Castalia.

La Voz de Galicia. La Coruña. Diciembre de 1991.

LÁZARO CARRETER, FERNANDO y CORREA CALDERÓN, EVARISTO. 1985. Cómo se comenta un texto literario. Madrid: Cátedra.

LÁZARO CARRETER, FERNANDO y TUSÓN, VICENTE. 1983. Curso de lengua española. Madrid: Anaya.

Suplemento TV. Madrid. 15-21 de mayo de 1993, no 290.

TUSÓN, VICENTE y LÁZARO CARRETER, FERNANDO. 1986. Literatura española. Madrid: Anaya.

VIZCAÍNO CASAS, FERNANDÚ. 1991. Entremeses variados. Barcelona: Planeta. 